\title{
Fiscal Policy and Budget Deficit Stability in a Continuous Time Stochastic Economy
}

\author{
João L. M. Amador* \\ Universidade Nova de Lisboa
}

13, November 1999

\begin{abstract}
This paper models the role of the fiscal policy and the behaviour of the budget deficit in a continuous time stochastic economy. The model is developed in a general equilibrium framework, integrating the optimisation behaviour of representative consumer and the intertemporal resource constraint of the fiscal authority. The main features of the model are the endogenous determination of the budget deficit as a percentage of deterministic output, the endogenous determination of the public bonds interest rate and the analysis of how changes in the structural and stochastic parameters affect the stationary equilibrium. In this context, we obtain conditions for the stability of the budget deficit. Finally, the paper simulates different scenarios and plots the stationary equilibrium path of the variables. The paper concludes that changes in the structural parameters of the model lead to unsustainable budget deficit behaviour. On the contrary, short-run shocks on technology and public expenditure are consistent with the stationary equilibrium. In addition, it is shown that the stationary equilibrium in economies having low tax rates and high public spending must be associated with a low public debt-wealth ratio and a low budget deficit. The same is true for economies that face high volatility in technology and expenditure shocks.
\end{abstract}

*Address: Faculdade de Economia da Universidade Nova de Lisboa, Travessa Estêvão Pinto (Campolide), 1099-032 Lisboa, Portugal. Tel: (351) 2138016 63, Fax: (351) 213886073 , e-mail: jamador@fe.unl.pt. The author thanks participants in the QED Meeting 99 (Bielefeld) for their comments and suggestions. 


\section{Contents}

1 Introduction 3

2 The Continuous Time Stochastic Economy 4

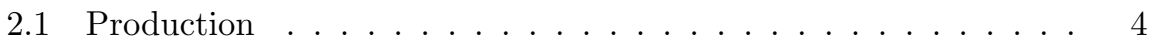

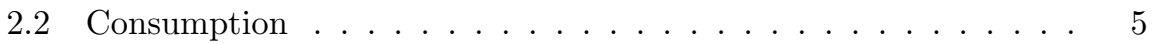

2.3 Optimum Conditions . . . . . . . . . . . . . . . . 7

3 Budget Deficits and the Public Bond Market 10

4 Partial Equilibrium Analysis 13

5 The General Equilibrium Solution 16

6 General Equilibrium Analysis $\quad 17$

6.1 The Effects of Public Expenditure and Taxation . . . . . . . . 19

6.2 The Effects of Technology and Expenditure Shocks . . . . . . . . 24

7 Simulated Equilibrium Path of Variables and Comparative Dynamics

8 Concluding Remarks $\quad 35$

A Appendix $\quad 36$

$\begin{array}{ll}\text { B Appendix } & 38\end{array}$ 


\section{Introduction}

The study of fiscal policy and budget deficits has been an active field of research in economic theory throughout the decades. This literature has addressed very different questions such as the consequences of running budget deficits, the optimal financing of budget deficits or the conditions required to avoid an unsustainable path for the public debt. Fiscal policy analysis has gained increased interest in the face of the new monetary union in Europe. In fact, public spending and taxation are the major policy instruments remaining available for the countries participating in the monetary union. Therefore, it is vital to know how countries should set fiscal parameters and their consequences on general macroeconomic performance. Furthermore, to run large budget deficits in a monetary union can become a serious problem. As a matter of fact, if a country cannot finance the budget deficit at any moment, it will either default, creating

a problem in the bond market of the monetary area, or be bailed out by a central authority. It is known that the domestic monetarisation of budget deficits is no longer an available solution in monetary unions. This type of concern has lead to the setting of guidelines for the budget deficits and public debt in the countries that would take part in the European Monetary Union. The Maastricht treaty transformed these guidelines into pre-entry conditions, and more recently, the Stability and Growth Pact adopted them as rules for the future of the monetary union. Therefore, it is very important to characterise the stationary equilibrium path of the budget deficit.

There are several studies focusing on these topics. Many of them examine the effects of fiscal policy and the budget deficits. A short and incomplete list of such studies includes Blanchard (1985), Barro (1989), Bernheim (1989), Emerson et al. (1992). Other studies clearly deal with the question of the sustainability of the budget deficit. In this group we include Nielsen (1992), Bohn (1995), Perotti, Strauch and von Hagen (1998) and Mongelli (1999).

The aim of this paper is to develop a general equilibrium continuous time stochastic model, stressing the role of fiscal policy and the behaviour of budget deficit and public debt. An important feature of the model is the definition of the sources of uncertainty as stochastic processes and the utilisation of stochastic optimisation methods, such as in Turnovsky (1995) and (1997). This author presents a general framework that is wider than the one adopted here, but assumes that taxation endogenously adjusts fiscal imbalances. We reduce the number of variables in the economy and focus instead on the endogenous determination of the public bond market equilibrium, and on its effects on the budget deficit. One of the simplifying assumptions is to consider a non-monetary economy. It is true that this hypothesis limits the analysis of important features such as inflation or the monetary financing of budget deficits. However, it may not be restrictive in the case of monetary unions where the central bank follows a low-inflation-oriented monetary policy and refuses to bail out single countries. This is clearly the case in the European Union. Another simplifying assumption is to consider a closed economy. This limits the ability of the government to sell public bonds abroad, which has obvious consequences on the budget deficit. 
Despite its importance, we argue later that this assumption does not change the main results of the paper and allows for a clear analysis of what is behind the sustainability of budget deficits. Within this framework, we endogenously obtain an expression for the equilibrium budget deficit as a percentage of deterministic output and an expression for the equilibrium public bond interest rate. In addition, it is possible to determine the equilibrium growth rate of the economy and the weight of capital stock and public bonds on total wealth. These results provide answers to some important questions, namely: knowing what the major determinants of the equilibrium budget deficit are, how to assure the sustainability of public debt, how the growth rate of the economy is affected by fiscal policy, and how uncertainty affects the results.

The paper concludes that changes on the tax rate, on average public spending and on the properties of the shocks that affect the economy lead to unsustainable budget deficit behaviour. These changes define structural shocks on the stationary equilibrium, which can only be compensated through additional changes in structural parameters. On the contrary, short-run shocks on technology and public expenditure are part of the stationary equilibrium and are consistent with budget deficit stability. In addition, it is shown that the stationary equilibrium in economies having low tax rates and high public spending must be associated with a low public debt-wealth ratio and a low budget deficit. The same is true for economies facing a high volatility on technology and expenditure shocks.

The paper is divided into eight sections. In the next section we present the continuous time stochastic economy. We describe production technology as well as the problem of the representative consumer. Next, we present the optimum conditions of the problem. In the third section we introduce public expenditure and define both budget deficits and public bond market equilibrium. Then, in the fourth section, a partial equilibrium analysis is presented. In the fifth section the general equilibrium solution of the model is obtained. Then, in the sixth section, we examine how changes in fiscal policy and uncertainty parameters affect the equilibrium. Moreover, we analyse the consequences of these changes in terms of the path of the deficit. In the seventh section, simulation methods are used to examine different scenarios and to plot the path of the variables in the stationary equilibrium. Finally, Section Eight presents some concluding remarks.

\section{The Continuous Time Stochastic Economy}

\subsection{Production}

The model considers a constant returns to scale technology, whose only input is the capital stock in the economy. Thus, the production function is of the type $Y=\alpha K$, where $\alpha$ is a technological parameter. Total output varies according to equation: 


$$
d Y=\alpha K d t+\alpha K d y
$$

This means that there exist stochastic technology shocks given by the second term of 1 , where $d y$ is a stochastic process with zero mean and variance $\sigma_{y}^{2}$. It is also assumed that the effect of these stochastic shocks is proportional to the size of the economy. From this, it follows that the implicit rate of return of the investment in capital stock is defined as:

$$
d R_{K}=\frac{d Y}{K}=\alpha d t+\alpha d y
$$

Later in the text, we will sometimes re-define the rate of return on capital as $d R_{K}=r_{K} d t+d k$, where $r_{K}=\alpha$ is the deterministic rate of return on capital and $d k=\alpha d y$ is the stochastic return component. This will be done only to simplify the notation.

\subsection{Consumption}

The model defines a representative consumer, whose utility function depends on the level of consumption in each period. Furthermore, consumers face an intertemporal resource constraint to be verified in each period. It is also assumed that output saved is transformed into additional wealth, which can be used either for investment in capital stock or for the buying of public bonds. Therefore, total wealth is the state variable of the problem and it plays an important role in the stationary equilibrium. We will designate total wealth by $W$, which is defined as:

$$
W \equiv B+K
$$

where $B$ stands for the stock of public bonds and $K$ for the capital stock. These are the only two assets in the economy.

As noted, the representative consumer maximises the expected discounted value of future consumptions. We assume an intertemporal discount rate $\beta$ and a utility function with constant elasticity of substitution between consumption at any two points in time, given by:

$$
U(C)=\frac{1}{\gamma} C(t)^{\gamma}
$$

where $\gamma \leq 1$ and $\gamma \neq 0^{1}$. The problem of the consumer is then:

$$
\operatorname{Max} E_{0} \int_{0}^{\infty} \frac{1}{\gamma} C(t)^{\gamma} e^{-\beta t} d t
$$

\footnotetext{
${ }^{1}$ The elasticity of substitution between consumption at any two points in time is constant and equal to $\frac{1}{1-\gamma}$. When attitudes towards risk are described, $(1-\gamma)$ has an alternative interpretation. It is then the coefficient of relative risk aversion, defined as $-\frac{u^{\prime \prime}(C) C}{u^{\prime}(C)}$. Therefore, this function is also called the constant relative risk aversion utility function (CRRA). Note also that when $\gamma=0$, the logarithmic utility function is obtained. This property will be used later in the text to simplify some results.
} 
The intertemporal resource constraint of the representative consumer provides the expression for the evolution of wealth. This intertemporal resource constraint is defined as:

$$
d W=\left(n_{B} d R_{B}+n_{K} d R_{K}\right) W-C(t) d t-d T
$$

where $n_{B}$ and $n_{K}$, stand respectively for the proportions of public bonds and capital on wealth. That is:

$$
\begin{aligned}
& n_{K}=\frac{K}{W} \\
& n_{B}=\frac{B}{W}
\end{aligned}
$$

Given the definition of wealth, another obvious condition is that $n_{B}+n_{K}=$ 1. Next, we turn to the definition of $d T$ and $d R_{B}$. These variables stand respectively for total taxes collected in each period and interest rate paid on public bonds. The model assumes the existence of taxes levied on total output. Output taxes are levied at a tax rate $\tau$ and generate stochastic tax receipts. In fact, if output is affected by stochastic shocks, so will be tax receipts ${ }^{2}$. Therefore, $d T$ represents total taxes collected in each period and it is defined as:

$$
d T=\tau \alpha K d t+\tau \alpha K d y
$$

Now we turn to the interest rate paid on public bonds. As observed above, public bonds are one of the two types of assets that exist in the economy. These bonds are issued by the fiscal authority in order to finance the budget deficit in each period. As a matter of fact, this is the only possible way of financing the budget deficit, because our assumption of a non-monetary economy excludes the possibility of monetary financing or the reduction of public liabilities through surprise inflation shocks. As we said in the first section, this hypothesis makes sense in monetary unions where the monetary policy is conducted by an independent and low-inflation-oriented central bank.

The interest rate paid on public bonds in each period is defined as:

$$
d R_{B}=r_{B} d t+d p
$$

where $r_{B}$ is a deterministic component and $d p$ is a stochastic shock, described by a stochastic process with zero mean and variance $\sigma_{p}^{2}$. It is important to stress that the deterministic and the stochastic components of public bonds interest rate are endogenously determined in the model. The continuous time stochastic economy that we have been describing, endogenously generates demand and supply of public bonds. On the one hand, consumers demand public bonds to include in their portfolios. This demand depends on structural parameters such

\footnotetext{
${ }^{2}$ It could be assumed that the tax rate was itself stochastic. That means it would contain both deterministic and stochastic components. This is the approach of Turnovsky (1995). We could also easily include taxes over wealth. However, that would not add much to the conclusions of the model.
} 
as preferences, the rate of return on capital investment, as well as the rate of return on public bonds. On the other hand, the model also generates an endogenous supply of public bonds. We recall that tax receipts depend on output and, further ahead, public spending will be presented in a similar way. Consequently, there will be an endogenously determined budget deficit, which is equivalent to an endogenously determined supply of public bonds. The equilibrium rate of return of public bonds will simply result from equating demand equal to supply.

Putting together all the definitions above, the intertemporal resource constraint of the representative consumer can be written as:

$$
\frac{d W}{W}=\left(n_{B} d R_{B}+n_{K} d R_{K}\right)-\frac{C}{W} d t-\frac{d T}{W}
$$

substituting equations 7 and 8, we rewrite the intertemporal resource constraint as:

$$
\frac{d W}{W}=\psi d t+d w
$$

where $\psi$ and $d w$ collect respectively the deterministic and the stochastic components. Therefore:

$$
\begin{aligned}
& \psi=n_{B} r_{B}+n_{K} r_{K}(1-\tau)-\frac{C}{W} \\
& d w=n_{B} d p+n_{K} r_{K}(1-\tau) d y
\end{aligned}
$$

At this point we have presented the problem of the representative consumer. In the next section the optimum conditions are determined.

\subsection{Optimum Conditions}

In this economy, the representative consumer chooses how much to consume in each period and how to compose the portfolio in terms of capital stock and public bonds. As a result, the control variables are the consumption-wealth ratio and the portfolio composition. That is, the proportion of capital on wealth and the proportion of public bonds on wealth. One important characteristic of these continuous time stochastic models is that these proportions are constant in the optimum. This defines stationarity between variables in the equilibrium.

Therefore, the representative consumer determines the optimal proportion of bonds on wealth, $n_{B}$, the optimal proportion of capital on wealth, $n_{K}$, and the optimal proportion of consumption on wealth, $C / W$, that maximise the discounted value of expected future utilities. That is:

$$
\underset{n_{B}, n_{K}, \frac{C}{W}}{\operatorname{Max}} E_{0} \int_{0}^{\infty} \frac{1}{\gamma}(C(t))^{\gamma} e^{-\beta t} d t
$$

subject to the intertemporal resource constraint previously derived:

$$
\frac{d W}{W}=\left(n_{B} r_{B}+n_{K} r_{K}(1-\tau)-\frac{C}{W}\right) d t+d w
$$


and subject to the condition that the sum of proportions equals one:

$$
n_{B}+n_{K}=1
$$

The stochastic optimisation techniques needed to solve the model are well presented in Malliaris and Brock (1982) and Turnovsky (1995). Here, we will briefly go through the main steps. The stochastic Lagrangian function of the problem is defined as:

$$
£=\frac{1}{\gamma}(C(t))^{\gamma} e^{-\beta t}+L_{W}\left[e^{-\beta t} X(W)\right]+e^{-\beta t} \lambda\left[1-n_{B}-n_{K}\right]
$$

where $\lambda$ is the Lagrangian multiplier of condition 15 and $L_{W}$ stands for the differential generator of the value function. The details of the derivation of the differential generator are presented in Appendix A. Using these results, the stochastic Lagrangian function becomes:

$$
\begin{aligned}
& £=\frac{1}{\gamma}\left(\frac{C}{W}\right)^{\gamma} W^{\gamma} e^{-\beta t}-\beta e^{-\beta t} X(W)+\left(\rho-\frac{C}{W}\right) W \frac{\partial X}{\partial W} e^{-\beta t}+ \\
& \frac{1}{2} \sigma_{w}^{2} W^{2} \frac{\partial^{2} X}{\partial W^{2}} e^{-\beta t}+e^{-\beta t} \lambda\left[1-n_{B}-n_{K}\right]
\end{aligned}
$$

where $X(W)$ is the value function of the problem and:

$$
\rho=n_{B} r_{B}+n_{K} r_{K}(1-\tau)
$$

is the net rate of return of the asset portfolio.

The first order conditions of the problem are the derivatives of equation 17 in order to the control variables and the Lagrangian multiplier. The derivatives in order to $C / W, n_{B}, n_{K}$ and $\lambda$ are respectively:

$$
\begin{gathered}
W^{\gamma}\left(\frac{C}{W}\right)^{\gamma-1}-W X_{W}=0 \\
r_{B} W X_{W}+\frac{1}{2} \frac{\partial \sigma_{w}^{2}}{\partial n_{B}} W^{2} X_{W W}-\lambda=0 \\
r_{K}(1-\tau) W X_{W}+\frac{1}{2} \frac{\partial \sigma_{w}^{2}}{\partial n_{K}} W^{2} X_{W W}-\lambda=0 \\
1-n_{B}-n_{K}=0
\end{gathered}
$$

Furthermore, deriving the variance of wealth in order to $n_{B}$ and $n_{K}$ we obtain respectively:

$$
\begin{aligned}
& \frac{\partial \sigma_{w}^{2}}{\partial n_{B}}=2 n_{B} \sigma_{p}^{2}+2 n_{K} r_{K}(1-\tau) \sigma_{p y} \\
& \frac{\partial \sigma_{w}^{2}}{\partial n_{K}}=2 n_{K} r_{K}^{2}(1-\tau)^{2} \sigma_{y}^{2}+2 n_{B} r_{K}(1-\tau) \sigma_{p y}
\end{aligned}
$$


Taking the two equations above, the optimum conditions are rewritten as:

$$
\begin{aligned}
& W^{\gamma}\left(\frac{C}{W}\right)^{\gamma-1}=W X_{W} \\
& r_{B} W X_{W}+\left(n_{B} \sigma_{p}^{2}+n_{K} \alpha(1-\tau) \sigma_{p y}\right) W^{2} X_{W W}-\lambda=0 \\
& r_{K}(1-\tau) W X_{W}+(1-\tau) \alpha\left(n_{K} \alpha(1-\tau) \sigma_{y}^{2}+n_{B} \sigma_{p y}\right) W^{2} X_{W W}-\lambda=0 \\
& \quad 1-n_{B}-n_{K}=0
\end{aligned}
$$

The other important optimum condition is the Bellman equation of the problem, given by:

$$
0=\frac{1}{\gamma} C^{\gamma}-\beta X(W)+\left(\rho-\frac{C}{W}\right) W \frac{\partial X}{\partial W}+\frac{1}{2} \sigma_{w}^{2} W^{2} \frac{\partial^{2} X}{\partial W^{2}}
$$

whose derivation is also presented in Appendix A.

An important step in the problems involving the Bellman equation is the determination of the value function, $X(W)$. In many problems, such as in the real business cycle literature, the only way to do this is through iterative computational methods. In our type of models, there is an a priori assumption for the value function. The point is to make equation 29 operational, in order to use it together with the first order conditions. In the end, it is possible to completely define the equilibrium, which means that the initial assumption for the value function was correct. Here, given the structure of the problem, we postulate a value function with the form:

$$
X(W)=\delta W^{\gamma}
$$

where $\delta$ is an unknown parameter. Making use of 30, conditions 25, 26 and 27 become respectively:

$$
\begin{gathered}
W^{\gamma}\left(\frac{C}{W}\right)^{\gamma-1}=\gamma \delta W^{\gamma} \\
r_{B} \gamma \delta W^{\gamma}+\left(n_{B} \sigma_{p}^{2}+n_{K} \alpha(1-\tau) \sigma_{p y}\right) \gamma(\gamma-1) \delta W^{\gamma}-\lambda=0 \\
r_{K}(1-\tau) \gamma \delta W^{\gamma}+(1-\tau) \alpha\left(n_{K} \alpha(1-\tau) \sigma_{y}^{2}+n_{B} \sigma_{p y}\right) \gamma(\gamma-1) \delta W^{\gamma}-\lambda=0
\end{gathered}
$$

Setting these last two conditions equal, we obtain:

$$
\begin{aligned}
& (1-\gamma)\left(n_{K} \alpha^{2}(1-\tau)^{2} \sigma_{y}^{2}+n_{B} \alpha(1-\tau) \sigma_{p y}-n_{B} \sigma_{p}^{2}-n_{K} \alpha(1-\tau) \sigma_{p y}\right)= \\
& \left(r_{K}(1-\tau)-r_{B}\right)
\end{aligned}
$$

This is a familiar equation in continuous time stochastic models and it displays an important result. As a matter of fact, the left hand side of 34 can 
be seen as the product of the coefficient of relative risk aversion $(1-\gamma)$ by the covariance between $d w$ and $r_{K}(1-\tau) d y-d p$. That is:

$$
(1-\gamma) \operatorname{Cov}\left(d w, r_{K}(1-\tau) d y-d p\right)=r_{K}(1-\tau)-r_{B}
$$

A risk averse consumer $(\gamma<1)$ optimally defines $n_{K}$ and $n_{B}$ so that the risk if faces from increased capital investment, priced at $(1-\gamma)$, equals the expected benefits of doing so. In the case of a risk neutral consumer $(\gamma=1)$, the optimum would obviously be to invest all wealth in the asset that presented a higher expected rate of return. Alternatively, equation 35 can be seen as defining the equilibrium risk premium between capital and public bonds.

Next, we use the two remaining optimum conditions, namely equations 29 and 31 , to obtain:

$$
\left(\frac{C}{W}\right)=\frac{1}{1-\gamma}\left[\beta-\gamma \rho-\frac{1}{2} \sigma_{w}^{2} \gamma(\gamma-1)\right]
$$

This is also a familiar equation in continuous time stochastic models. It defines the optimum proportion of consumption on wealth. The analysis of 36 is very well presented in Turnovsky (1995) and we just review the main insights. As would be expected, the optimum proportion of consumption on wealth depends positively on the intertemporal discount rate. In fact, larger intertemporal discount rates shift consumption from the future to the present, decreasing investment. Secondly, an increase in the deterministic net return of the portfolio $\rho$ raises the consumption-wealth ratio when $\gamma<0$. There are two effects at stake, namely an income effect, which increases consumption, and a substitution effect, which decreases it. When $\gamma<0$, the income effect dominates the substitution effect. An increase in the variance of wealth $\sigma_{w}^{2}$, can be decomposed in an analogous way. As long as the agent is risk averse, an increase in the variance means a reduction in income, leading to a reduction in consumption. However, the higher variance turns savings more risky, leading to a shift towards consumption. When $\gamma<0$, the first effect dominates.

In the next section we complete the presentation of fiscal policy by modeling the behaviour of public expenditure. Then, it will be possible to define the budget deficit and the public bond market equilibrium.

\section{Budget Deficits and the Public Bond Market}

Before presenting the equation that describes the budget deficit, it is necessary to define the behaviour of public expenditure. It is assumed that public expenditure is proportional to output and includes a stochastic component, $d z$, with zero mean and variance $\sigma_{z}^{2}$. Thus, we define the stochastic process that describes the evolution of public expenditure as:

$$
d G=g \alpha K d t+\alpha K d z
$$


This hypothesis describes a situation where the fiscal authority spends a given proportion of output plus a stochastic amount of resources. The stochastic component of expenditure is proportional to output and traduces the shortrun behaviour of spending. It may include short-run fiscal policy adjustments or the effects of the automatic stabilisers. On the contrary, the deterministic component defines the long-run expenditure policy. At this point, having defined both taxation and public expenditure, it is easy to define the budget deficit in the economy as:

$$
d B=d G+B d R_{B}-d T
$$

where $d B$ stands for the budget deficit, which is also equal to the amount of new debt created in each period. As mentioned above, the model assumes that the fiscal authority issues new bonds to finance the budget deficit in each period. In other words, there is a perfectly rigid supply of public bonds.

Combining equations $38,37,7$ and 8 , we rewrite the expression for the budget deficit as:

$$
d B=\left[(g-\tau) \alpha K+B r_{B}\right] d t+d b
$$

where:

$$
d b=\alpha K d z-\tau \alpha K d y+B d p
$$

As expected, the budget deficit is higher, the higher the difference between the public expenditure parameter $g$ and the tax rate $\tau$, the higher the amount of existing debt $B$ and the higher the debt interest rate $R_{B}$. In addition, the deficit increases with the difference between stochastic expenditure and stochastic tax receipts.

The next step is to determine the public bond market equilibrium. First, we re-define the budget deficit. This variable is usually presented as a proportion of output. However, the output that is generated in our economy contains a stochastic element, which turns the budget deficit-output ratio into a ratio of two stochastic processes. It is very difficult to keep track of such a variable. Due to this, we chose to compute the budget deficit as a proportion of the deterministic element in output. In other words, we work with the budget deficit-average output ratio. Note that it would be possible to compute the budget deficit as a proportion of any other non-stochastic variable. This would not change the public bond market equilibrium. Nevertheless, our choice is suitable because it allows a reasonable calibration of the model and a realistic illustration of the stationary equilibrium.

The average output is defined as:

$$
Y^{D}=\alpha K
$$

Therefore, the supply of public bonds as a proportion of average output is written as:

$$
\frac{d B}{Y^{D}}=\left(g-\tau+\frac{n_{B}}{\alpha n_{K}} r_{B}\right) d t+d z-\tau d y+\frac{n_{B}}{\alpha n_{K}} d p
$$


To obtain the demand of public bonds as a proportion of average output we make use of the properties of the equilibrium. As mentioned, the optimal proportion of each asset on total wealth is constant in the equilibrium. Therefore, since there is no change in the public bond-wealth ratio, we can write:

$$
d\left(\frac{B}{W}\right)=0
$$

which, using Itô's lemma, is equivalent to:

$$
\frac{d B}{Y^{D}}=\left(\frac{n_{B}}{\alpha n_{K}}\right) \frac{d W}{W}
$$

Finally, using the equation 6 , which describes the evolution of wealth through time, we obtain:

$$
\frac{d B}{Y^{D}}=\left(n_{B}(1-\tau)+\frac{n_{B}^{2} r_{B}}{\alpha n_{K}}-\frac{n_{B}}{\alpha n_{K}} \frac{C}{W}\right) d t+n_{B}(1-\tau) d y+\frac{n_{B}^{2}}{\alpha n_{K}} d p
$$

It is important to note that this equation for the demand of public bonds is obtained using no equilibrium properties. In fact, none of the first order conditions that come from the problem of the representative consumer were used. What is said is that, given the optimal portfolio composition $n_{K}$ and $n_{B}$, there is an endogenous growth rate of wealth, which gives rise to a public bond demand. The optimal consumer decisions are included in the values of $n_{K}$ and $n_{B}$.

Since the optimal asset-wealth ratios are defined as constants, and taking $r_{B}$ and $d p$ at their equilibrium values, equation 45 defines the budget deficit as a proportion of deterministic output. It is given by a Brownian motion with average and variance defined respectively as:

$$
\begin{gathered}
\mu=n_{B}(1-\tau)+\frac{n_{B}^{2} r_{B}}{\alpha n_{K}}-\frac{n_{B}}{\alpha n_{K}} \frac{C}{W} \\
\sigma^{2}=n_{B}^{2}(1-\tau)^{2} \sigma_{y}^{2}+\left(\frac{n_{B}^{2}}{\alpha n_{K}}\right)^{2} \sigma_{p}^{2}+2(1-\tau) \frac{n_{B}^{3}}{\alpha n_{K}} \sigma_{y p}
\end{gathered}
$$

Equivalently, taking equation 42 , which defines the supply of public bonds, we obtain:

$$
\begin{gathered}
\mu=g-\tau+\frac{n_{B}}{\alpha n_{K}} r_{B} \\
\sigma^{2}=\sigma_{z}^{2}+\tau^{2} \sigma_{y}^{2}+\left(\frac{n_{B}}{\alpha n_{K}}\right)^{2} \sigma_{p}^{2}+2\left(-\tau \sigma_{z y}+\frac{n_{B}}{\alpha n_{K}} \sigma_{p z}-\tau \frac{n_{B}}{\alpha n_{K}} \sigma_{p y}\right)
\end{gathered}
$$

The public bond market equilibrium is obtained putting together supply and demand. In fact, equaling the deterministic and stochastic components of demand and supply of public bonds, we obtain $r_{B}$ and $d b$ as:

$$
r_{B}=\frac{\alpha n_{K}}{n_{B}^{2}-n_{B}}\left[(g-\tau)-n_{B}(1-\tau)+\frac{n_{B}}{\alpha n_{K}} \frac{C}{W}\right]
$$




$$
d p=\frac{\alpha n_{K}}{n_{B}^{2}-n_{B}}\left[d z-\tau d y-n_{B}(1-\tau) d y\right]
$$

which, using the condition that $n_{K}+n_{B}=1$, simplifies to:

$$
\begin{gathered}
r_{B}=-\frac{\alpha}{n_{B}}\left[(g-\tau)-n_{B}(1-\tau)+\frac{n_{B}}{\alpha\left(1-n_{B}\right)} \frac{C}{W}\right] \\
d p=-\frac{\alpha}{n_{B}}\left[d z-\tau d y-n_{B}(1-\tau) d y\right]
\end{gathered}
$$

It is also possible to endogenously determine the variance of the public bonds interest rate and the covariance between technology shocks and bond interest rate shocks. They are given by:

$$
\begin{aligned}
\sigma_{p}^{2} & =\left(\frac{\alpha}{n_{B}}\right)^{2}\left(\sigma_{z}^{2}+\tau^{2} \sigma_{y}^{2}+n_{B}^{2}(1-\tau)^{2} \sigma_{y}^{2}\right. \\
& \left.-2 \tau \sigma_{y z}-2 n_{B}(1-\tau)\left(\sigma_{y z}-\tau \sigma_{y}^{2}\right)\right) \\
\sigma_{p y}= & -\frac{\alpha}{n_{B}}\left(\sigma_{y z}-\tau \sigma_{y}^{2}-n_{B}(1-\tau) \sigma_{y}^{2}\right)
\end{aligned}
$$

Note that the equilibrium in the public bonds market depends on the optimal values of $C / W, n_{K}$ and $n_{B}$, which are, themselves a function of the bond market equilibrium. In order to obtain the solution of the general equilibrium model, it is necessary to determine the expressions of $C / W, n_{K}$ and $n_{B}$. This will be done in Section Five. Meanwhile, the properties of the partial equilibrium solution are analysed.

\section{Partial Equilibrium Analysis}

Observing equation 52 and taking $C / W, n_{K}$ and $n_{B}$ as constants, we conclude that an increase in the public expenditure parameter $g$ decreases the equilibrium average interest rate on public bonds $r_{B}$. It is important to discuss this point. It might be expected that increased spending would lead to a higher equilibrium rate of return on public bonds. It is certain that an increase in $g$ leads to higher budget deficits, which need to be financed through an increased supply of public bonds. However, it is necessary to examine the conditions under which consumers are willing to hold these bonds in equilibrium. Equation 46 says that such an increase in demand must come about through an increase in $r_{B}$, which increases wealth growth rate. However, equation 48 shows that a rise in $r_{B}$ also increases the supply of public bonds. This happens because a higher $r_{B}$ increases the amount of interest paid on the stock of public debt. Thus, there are two opposite effects. Since $n_{B}$ is less than one, the second effect dominates, meaning that an increase in $r_{B}$ worsens the budget deficit and enlarges the excess supply of public bonds. As a matter of fact, in order to keep $n_{B}$ constant, the representative consumer wishes to increase the stock of public bonds by less than the increase in $W$. This situation means that the stationary

partial equilibrium in the public bond market is unstable. In other words, the 
Figure 1: Effect of an Increase in $g$

Figure 2: Increase in $g$ adjusted by a decrease in $C / W$

response of the average demand of public bonds to a marginal increase in $r_{B}$, $\left(\frac{n_{B}^{2}}{\alpha n_{K}}\right)$, is smaller than the response of the average supply, $\left(\frac{n_{B}}{\alpha n_{K}}\right)$. Figure 4.1 illustrates this phenomenon.

In this sense, an increase in $g$ leads to repeated and larger increases in the budget deficit, which correspond to an unsustainable path for public debt. The return to a stationary equilibrium must come about through another change in parameters. In our example the fiscal authority could try to return to a stationary equilibrium by reducing $g$ or increasing $\tau$. However, the increase in $\tau$ would have immediate consequences both on average supply and demand of public bonds. In figure 4.2 we show the case of an increase in $g$ that is adjusted by a hypothetical decrease in $C / W$. In this situation the economy is easily placed in a new stationary equilibrium.

The analysis of shocks on the remaining deterministic variables involves the same type of approach that we have described above, proving again the existence of an unstable stationary partial equilibrium. In addition, to completely define the stationary equilibrium, it is necessary that the stochastic components on demand and supply of public bonds equalise in each period. In this case, it is the stochastic component of the interest rate $(d p)$ that adjusts, assuring that the public bonds are sold. In this context, it makes no sense to examine the response of $d p$ to shocks. As a matter of fact, in each moment, the economy faces both technological and expenditure shocks, which can be positive or negative. Therefore, contrary to the equilibrium above, which centres on the trend of the variables, this short-run stochastic equilibrium poses no problems in terms of stability. The relevant variable in this case is simply the variance of $d p$, defined above as $\sigma_{p}^{2}$.

At this point, it is important to discuss the effects of alternative ways of financing the budget deficit that are not explicitly considered in the model. In general, it can be said that the main results do not change. Take the cases of raising revenues through the sale of public assets (such as privatising), through surprise inflation shocks or through an increase in the stock of money. If we had considered the possibility of raising revenues through the sale of public assets, it would not change the results obtained. In fact, that kind of additional revenue cannot be considered a permanent financing alternative. The stock of public assets is limited and no government can permanently use that alternative. Therefore, an increase in average public expenditure could be initially financed in this manner, but it would eventually lead to the same stability problems 
Figure 4.1: Effect of an increase in $g$

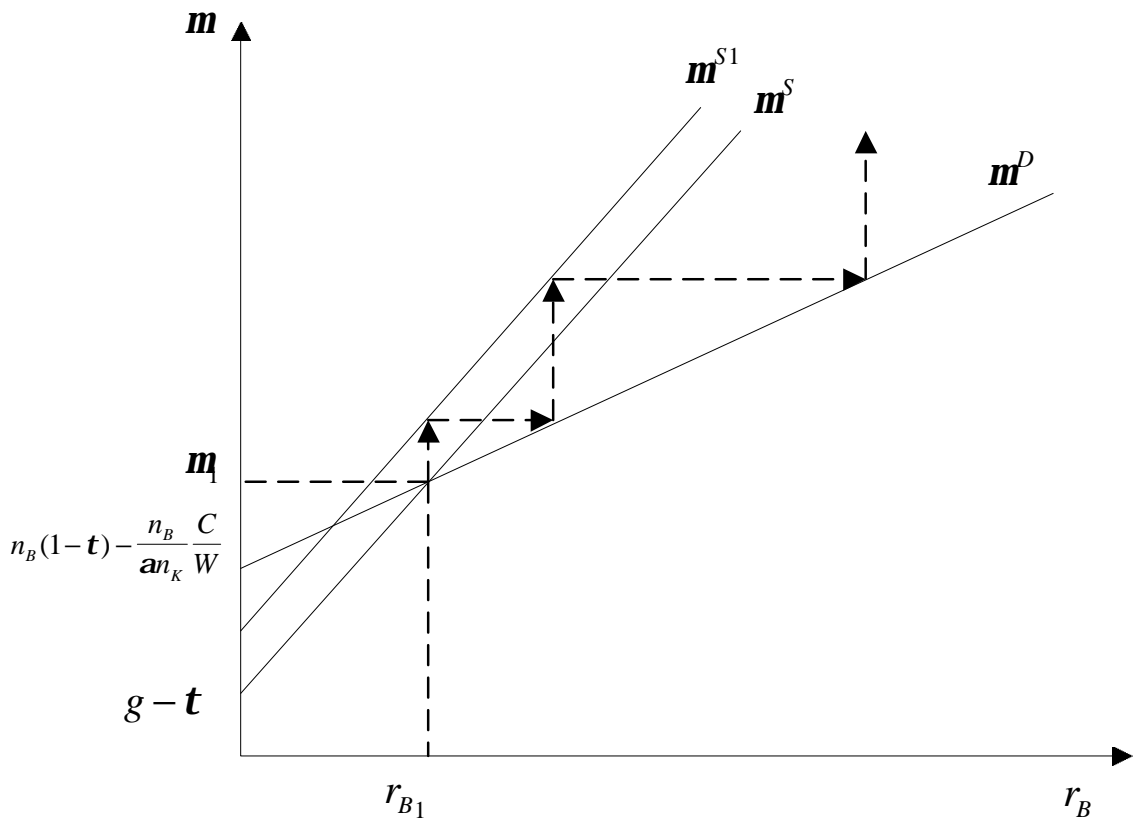


Figure 4.2: Increase in $g$ adjusted by a decrease in $C / W$

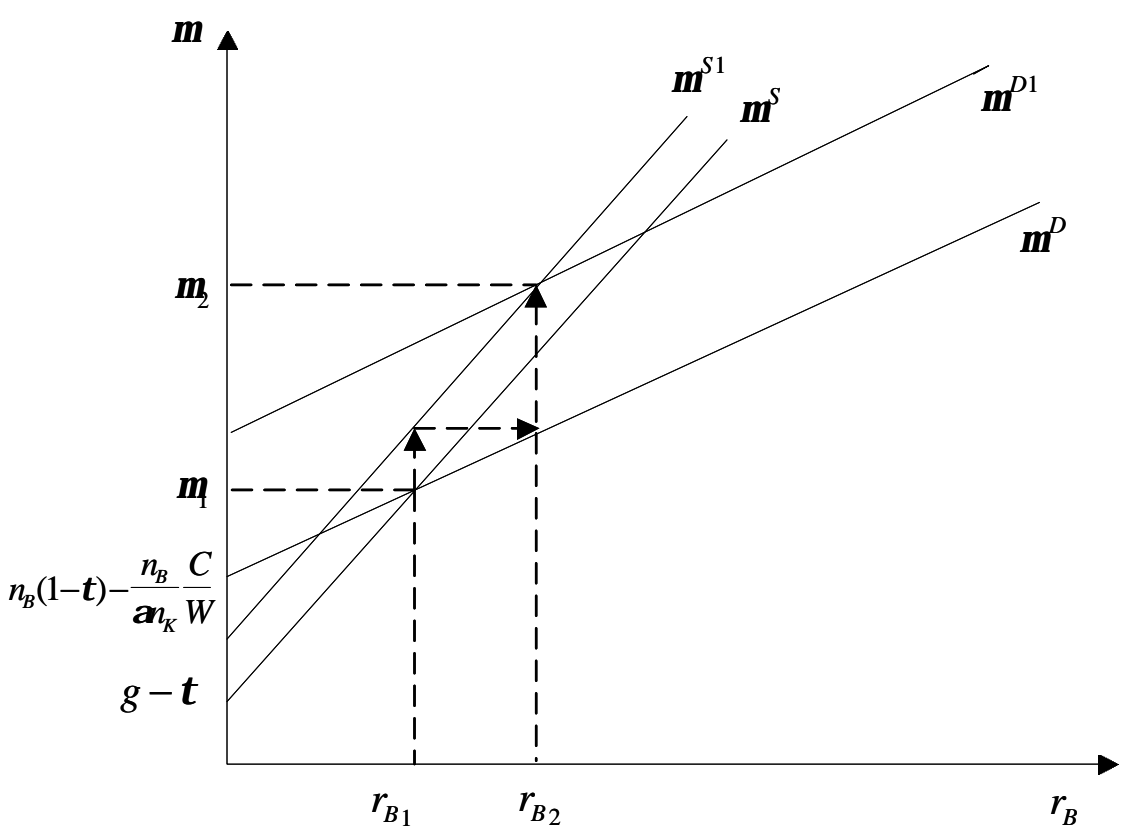


that we mentioned above. A surprise inflation shock is another alternative. It decreases the real value of existing debt, which leads to a decrease in public liabilities. However, here again, this cannot be an option in the stationary equilibrium. By definition, these shocks must remain as surprises and cannot be permanently used in the equilibrium. Next, we briefly discuss the monetary financing alternative. In this case, the model would have to be enlarged to include money as a third asset. In addition, it would be necessary to include the stock of money as a parameter of the utility function or include a cash-inadvance constraint. Therefore, money would be part of the optimal portfolio in the same way as capital and public bonds. The equilibrium conditions would be far more complex, but the optimal proportion of money in total wealth would still be constant. In the stationary equilibrium there would be a demand for money, which would partially finance the deficit. However, a hypothetical shock in $g$, or in any other variable, would still generate the same stability problems mentioned above. Finally, we discuss the implications of the closed economy assumption. These implications differ according to the size of the economy. In the case of a small open economy with perfect capital mobility, the interest rate on public bonds is given. Therefore, it would be possible to finance an increase in the budget deficit by selling bonds on the foreign market, without raising $r_{B}$. In Figure 4.1 the adjustment to the increase in $g$ would result from nothing more than the vertical shift in the average public bond supply, keeping the same $r_{B_{1}}$. In the case of a large economy, there are still adjustments in the average public bond interest rate. In fact, domestic and foreign consumers would only be willing to hold larger quantities of bonds if the interest rate increased. This would lead to the same stability problems mentioned above. Nevertheless, a rigorous analysis of the effects of budget deficit financing in open economies would demand the explicit consideration of demand and supply of foreign bonds, which would be held by domestic and foreign consumers. Such an extension greatly increases the complexity of the model, without providing additional significant insights.

At this point, it is important to recall that we have made a strictly partial equilibrium analysis. In fact, changes in the public bond market do affect the optimum values of $C / W, n_{B}$ and $n_{K}$, which, in turn, affect the public bond market equilibrium. Before moving to the general equilibrium solution of the model, we recall the endogenous and exogenous parameters that have been introduced so far. The control variables are the consumption-wealth ratio, $C / W$, the capital-wealth ratio, $n_{K}$, and the public bond-wealth ratio, $n_{B}$. The exogenous parameters of the model are $g$, for public expenditure, $\tau$ for the output tax rate, $\alpha$ as a technological parameter, $\gamma$ as a utility function parameter and $\beta$ for the intertemporal discount rate. Then, there is the average rate of return on public bonds $r_{B}$, which is endogenously determined. As for the stochastic components, there is $d y$, which describes technology shocks and $d z$, which describes public expenditure shocks. The variances of these shocks are respectively $\sigma_{y}^{2}$ and $\sigma_{z}^{2}$, and their covariance is designated by $\sigma_{y z}$. Next, the stochastic component of the rate of return on public bonds $d p$ is endogenously determined and its variance is given by $\sigma_{p}^{2}$. Finally, the average budget deficit-output ratio and 
its variance are given respectively by $\mu$ and $\sigma^{2}$.

\section{The General Equilibrium Solution}

In this section we derive the general equilibrium solution of the model, where the optimal asset-wealth ratios and the budget deficit are defined as functions of the structural parameters of the economy. The first step is to compute the variance of wealth $\sigma_{w}^{2}$, needed for the definition of the optimum condition 36. Recall that the stochastic return on the portfolio was previously defined in equation 12 as:

$$
d w=n_{B} d p+n_{K} \alpha(1-\tau) d y
$$

Taking together equation 53 and condition $n_{K}+n_{B}=1$, the stochastic component of wealth can be rewritten as:

$$
d w=-\alpha d z+\alpha d y
$$

to which corresponds the variance:

$$
\sigma_{w}^{2}=\alpha^{2}\left(\sigma_{y}^{2}+\sigma_{z}^{2}-2 \sigma_{y z}\right)
$$

The next step is the complete definition of the first order condition 35, that is:

$$
\operatorname{Cov}(d w, \alpha(1-\tau) d y-d p)=(1-\gamma)^{-1}\left(r_{K}(1-\tau)-r_{B}\right)
$$

Putting together equations 56, 52 and 53, this optimum condition can be rewritten as:

$$
(1-\gamma)^{-1}\left[\alpha(g-\tau)+\frac{n_{B}}{\left(1-n_{B}\right)} \frac{C}{W}\right]=\alpha^{2}\left((1+\tau) \sigma_{y z}-\sigma_{z}^{2}-\tau \sigma_{y}^{2}\right)
$$

At this point we put together the set of equations that defines the general equilibrium solution of the model. Taking equations 18,36 and 58, the optimum is defined by the following two-equation non-linear system.

$$
\begin{gathered}
\frac{C}{W}=\frac{1}{1-\gamma}\left\{\beta+\gamma \alpha\left[(g-\tau)-n_{B}(1-\tau)+\frac{n_{B}}{\alpha\left(1-n_{B}\right)} \frac{C}{W}\right]-\right. \\
\left.\gamma \alpha(1-\tau)\left(1-n_{B}\right)\right\}+\frac{1}{2} \gamma \alpha^{2}\left(\sigma_{y}^{2}+\sigma_{z}^{2}-2 \sigma_{y z}\right) \\
\frac{n_{B}}{\left(1-n_{B}\right)} \frac{C}{W}=-\alpha(g-\tau)+(1-\gamma) \alpha^{2}\left((1+\tau) \sigma_{y z}-\sigma_{z}^{2}-\tau \sigma_{y}^{2}\right)
\end{gathered}
$$

Finally, there are two no-ponzy game conditions. The first states that, when $t \rightarrow \infty$, the expected discounted value of wealth is zero.

$$
\lim _{t \rightarrow \infty} E\left[W^{\gamma} e^{-\beta t}\right]=0
$$


The transversality condition above is met when $C / W>0$. This is demonstrated in Turnovsky (1995). In fact, given equation 10, total wealth at moment $t$ can be written as:

$$
W(t)=W(0) e^{\left(n_{B} r_{B}+n_{K} \alpha(1-\tau)-\frac{C}{W}-\frac{1}{2} \sigma_{w}^{2}\right) t}+w(t)-w(0)
$$

Therefore, the transversality condition is met if and only if:

$$
\gamma\left(n_{B} r_{B}+n_{K} \alpha(1-\tau)-\frac{C}{W}-\frac{1}{2} \sigma_{w}^{2}\right)-\beta<0
$$

which, using equation 36 , is verified if $C / W>0$. Furthermore, the expected discounted value of public debt when $t \rightarrow \infty$ must also be zero.

$$
\lim _{t \rightarrow \infty} E\left[B e^{-\beta t}\right]=0
$$

Note that this second transversality condition is met under the same circumstances as the first one. In fact, if $n_{B}$ is constant in the optimum and the expected discounted value of future wealth is zero, then the expected discounted value of public debt must also be zero.

Having defined the solution, it is now possible to obtain the stochastic process that describes the path of the budget deficit in the stationary equilibrium. This is done by taking the optimal values of the control variables and substituting equations 52 and 53 on 46 and 47 , or alternatively on 48 and 49 . The result is necessarily identical in either option and equal to:

$$
\begin{gathered}
\mu=\frac{n_{B}}{1-n_{B}}\left[1-g-\frac{1}{\alpha\left(1-n_{B}\right)} \frac{C}{W}\right] \\
\sigma^{2}=\left(\frac{n_{B}}{1-n_{B}}\right)^{2}\left(\sigma_{z}^{2}+\sigma_{y}^{2}-2 \sigma_{z y}\right)
\end{gathered}
$$

The next section examines the properties of the general equilibrium solution and the effects of changes on policy and stochastic parameters.

\section{General Equilibrium Analysis}

The previous section presented the set of non-linear equations that defines the equilibrium values of the control variables. At this point, we simplify the analysis and take the case of the logarithmic utility function. This type of utility function is an important benchmark in the literature and it means that the elasticity of substitution between consumption at any two points in time is equal to one. In our model, this is equivalent to setting $\gamma=0$, which through equation 59 implies $C / W=\beta$. This is a familiar result in the literature. Since wealth represents future consumption possibilities, a unitary elasticity of substitution means that discounted future consumption must equal present consumption. 
Having defined the consumption-wealth ratio, the optimal $n_{B}$, which is given by equation 60 , becomes:

$$
n_{B}=\frac{-\alpha(g-\tau)+\alpha^{2}\left((1+\tau) \sigma_{y z}-\sigma_{z}^{2}-\tau \sigma_{y}^{2}\right)}{\beta-\alpha(g-\tau)+\alpha^{2}\left((1+\tau) \sigma_{y z}-\sigma_{z}^{2}-\tau \sigma_{y}^{2}\right)}
$$

The general equilibrium solution of the model is best understood if we recall the partial equilibrium analysis. It was said that shocks on the structural parameters of the model lead to unsustainable budget deficit behaviour. We arrived at that conclusion by taking the asset-wealth ratios fixed. Now, it is important to examine the general equilibrium behaviour of the budget deficit defined by equations 58 and 66 . In this case the optimal asset-wealth ratios are not constant. As a matter of fact, changes in structural parameters lead to changes in the public bond market, which lead to changes in the optimum values of $n_{K}$ and $n_{B}$. These changes in turn affect the public bond market and so on, until a new equilibrium in reached. As we have seen, these relationships are highly non-linear and the equilibrium may be stable or unstable depending on the values assumed by the structural parameters of the economy. In this general equilibrium context, it is not possible to define stability by comparing the derivative of the demand and supply of bonds in order to changes in the interest rate. As we have observed above, the public bond interest rate is an endogenous variable that depends on the optimal $n_{B}$, which is itself endogenous. Nevertheless, it is possible to analyse the initial effects of $r_{B}$ on $n_{B}$, leaving aside the subsequent effects of $n_{B}$ on $r_{B}$. Therefore, taking equations 46 and 48 , and differentiating in order to $r_{B}$, we obtain:

$$
\begin{aligned}
\left(\frac{\partial \mu}{\partial r_{B}}\right)^{D} & =(1-\tau) \frac{\partial n_{B}}{\partial r_{B}}+\frac{1}{\alpha}\left(\frac{2 n_{B}-n_{B}^{2}}{\left(1-n_{B}\right)^{2}} \frac{\partial n_{B}}{\partial r_{B}} r_{B}+\frac{n_{B}^{2}}{1-n_{B}}\right) \\
- & \frac{\beta}{\alpha} \frac{1}{\left(1-n_{B}\right)^{2}} \frac{\partial n_{B}}{\partial r_{B}} \\
\left(\frac{\partial \mu}{\partial r_{B}}\right)^{S} & =\frac{1}{\alpha}\left(\frac{1}{\left(1-n_{B}\right)^{2}} \frac{\partial n_{B}}{\partial r_{B}} r_{B}+\frac{n_{B}}{1-n_{B}}\right)
\end{aligned}
$$

where the derivative of the optimal $n_{B}$ in order to $r_{B}$ results from equation 34 and is given by:

$$
\frac{\partial n_{B}}{\partial r_{B}}=\frac{1}{\alpha^{2}(1-\tau)^{2} \sigma_{y}^{2}+\sigma_{p}^{2}-2 \alpha(1-\tau) \sigma p y}>0
$$

where $\sigma_{p}^{2}$ and $\sigma_{p y}$ are taken as fixed. Note that these parameters are endogenously determined in the model and come from the equilibrium in the stochastic component of the public bond market. In this partial analysis we take them as fixed as a way of eliminating the subsequent effects of changes on $n_{T}$ over $r_{B}$. In this sense, an important indicator of budget deficit stability would still be 
the observation that an increase in the average rate of return on public bonds leads to excess demand in the market. That is:

$$
\left(\frac{\partial \mu}{\partial r_{B}}\right)^{D}>\left(\frac{\partial \mu}{\partial r_{B}}\right)^{S}
$$

It is not possible to establish a clear relationship between 68 and 69 . Nevertheless, there are restrictions to be imposed on the acceptable values for the parameters. On the one hand, there are technical restrictions, such as imposing that $n_{K}, n_{B}$ and $C / W$ assume values between zero and one. In addition, the variance of technology and expenditure shocks $\left(\sigma_{y}^{2}\right.$ and $\left.\sigma_{z}^{2}\right)$, the variance of public bond interest rate $\left(\sigma_{p}^{2}\right)$ and the variance of the budget deficit $\left(\sigma^{2}\right)$ must always be positive. On the other hand, it is necessary to assume realistic values for the structural parameters. In this sense, neither the tax rate nor the public spending-output ratio should be set superior to one. Given these two types of restrictions it is possible to arrive at two initial conclusions. Firstly, taking reasonable values for the parameters, it is seen that a stationary equilibrium cannot coexist with an average primary budget deficit. In other words, if $g>\tau$ there is no feasible stationary equilibrium. In such a situation the country would not run the primary surplus needed to finance the interest paid on the public debt. This result comes as no surprise. Secondly, for reasonable values of the parameters, the stationary general equilibrium solution remains unstable. Therefore, shocks on deterministic parameters still lead to growing deficits or surpluses. A sufficient condition to assure unstable behaviour is:

$$
\left(1-n_{B}\right)^{2} \alpha(g-\tau)-n_{B}^{2} \beta<0
$$

which, is always verified when $g<\tau$. Recall that we have argued that an average primary budget surplus was necessary to assure the existence of a feasible stationary equilibrium. It is important to stress that we have not developed a complete analysis of the stability of the general equilibrium. However, it was possible to establish that, ignoring the subsequent effects of $n_{B}$ on $r_{B}$, the equilibrium remains unstable. This unstable behaviour for the budget deficit is not a surprise. The classical approach to the sustainability of public finances states that same result and derives a condition for the stability of the debt-income ratio. We briefly derive that condition in Appendix B. In a sense, our paper deals with the same issue but in a dynamic, general equilibrium and stochastic framework. In the next two subsections we examine the complete general equilibrium adjustment of the endogenous variables to shocks in the parameters of the model.

\subsection{The Effects of Public Expenditure and Taxation}

This subsection examines the adjustment of the endogenous variables of the model to changes in public expenditure and taxation. In particular, we aim to analyse the effect of changes on the public expenditure-output ratio and on the tax rate. Therefore, the analysis is conducted only in average terms, leaving 


\begin{tabular}{|c|c|c|c|c|c|c|c|}
\hline Parameter & $\alpha$ & $\beta$ & $g$ & $\tau$ & $\sigma_{y}^{2}$ & $\sigma_{z}^{2}$ & $\sigma_{y z}$ \\
\hline Value & 0.15 & 0.05 & 0.25 & 0.3 & 0.01 & 0.01 & 0.0000 \\
\hline Parameter & $n_{B}$ & $n_{K}$ & $\mu$ & $r_{B}$ & $\sigma_{p}^{2}$ & $\sigma_{p y}$ & $\sigma^{2}$ \\
\hline Value & 0.13 & 0.87 & 0.05 & 0.11 & 0.02 & 0.005 & 0.0004 \\
\hline
\end{tabular}

Table 1: Base Parameters

aside the short-run technology and expenditure shocks. To proceed with this type of analysis, it is necessary to revert to a discrete time framework and to include some additional hypothesis concerning the timing and speed of the adjustment. In fact, by taking a second order linearisation of equations 34,42 , 45,54 and 55 , it is possible to establish the dynamics of the adjustments in the model. As in section four, we assume that there is a rigid supply of public bonds in each period, which is adjusted by changes in the average interest rate. In the next period, the change in the interest rate leads to a recomposition of the optimal portfolio, which leads again to a different demand of public bonds. The adjustment proceeds in this way. Note that the changes in the optimal portfolio are also due to changes in parameters $\sigma_{p}^{2}$ and $\sigma_{p y}$, which are themselves endogenous. It is assumed that these parameters begin their adjustment only in the second period after the shock. This is the time necessary for the initial portfolio rearrangement to exert its effects. Additionally, we assume that each asset cannot change its weight in the portfolio more than two percent in each period. This simply delays the adjustment process and it is equivalent to considering that there are transaction costs or imperfect information in portfolio management. This assumption is included to ensure that, in case of divergent behaviour, $n_{K}$ and $n_{B}$ do not immediately jump to values that are not realistic. The results obtained are robust to changes in the limiting value of two percent. Finally, the values assumed for the exogenous parameters are presented in Table 6.1, which also contains the resulting values for the endogenous parameters. This calibration was chosen in order to assure reasonable values for all the parameters and does not intend to describe any particular economy.

Given this framework, we start by examining the adjustment to a one percent increase in the public expenditure parameter $(\Delta g=0.01)$. Figure 6.1 plots this adjustment. As would be expected, the increased spending leads to an initial increase in the average supply of public bonds. As a consequence, the average public bond interest rate must increase to prompt consumers to hold a larger proportion of bonds in the optimal portfolio. In the moment following the shock the adjustment continues. The portfolio recomposition that occurred in the first moment changes both the variance of the public bond interest rate and the covariance between technological and interest rate shocks. There are also additional changes both on demand and supply of public bonds. On the one hand, the higher $r_{B}$ gives rise to an increased supply of bonds. On the other hand, the higher values for $r_{B}$ and $n_{B}$ lead to a new demand for bonds. Combining the new demand and supply, we obtain a higher equilibrium $r_{B}$. This new average interest rate acts together with the new values for $\sigma_{p}^{2}$ and $\sigma_{p y}$, 
further increasing the optimal $n_{B}$. Looking at Figure 6.1, it can be seen that the adjustment continues and tends to reinforce the initial increase in the average budget deficit and in the average public bond interest rate. As expected, the initial stationary equilibrium proves to be unstable.

The adjustment to a one percent decrease in the tax rate $(\Delta \tau=-0.01)$ is examined in the same way as the increase in public spending. Not surprisingly, Figure 6.2 plots an adjustment that is similar to the one obtained before. In fact, despite being a parameter that affects more deeply the expressions for $n_{B}$, $\mu, \sigma_{p}^{2}$ and $\sigma_{p y}$, the decrease in $\tau$ produces effects that are close to those of an increase in $g$. Nevertheless, it is seen that a one percent decrease in $\tau$ tends to be slightly less damaging than the one percent increase in $g$. 
Figure 6.1: Adjustment to an Increase in Parameter $g(\Delta g=0.01)$
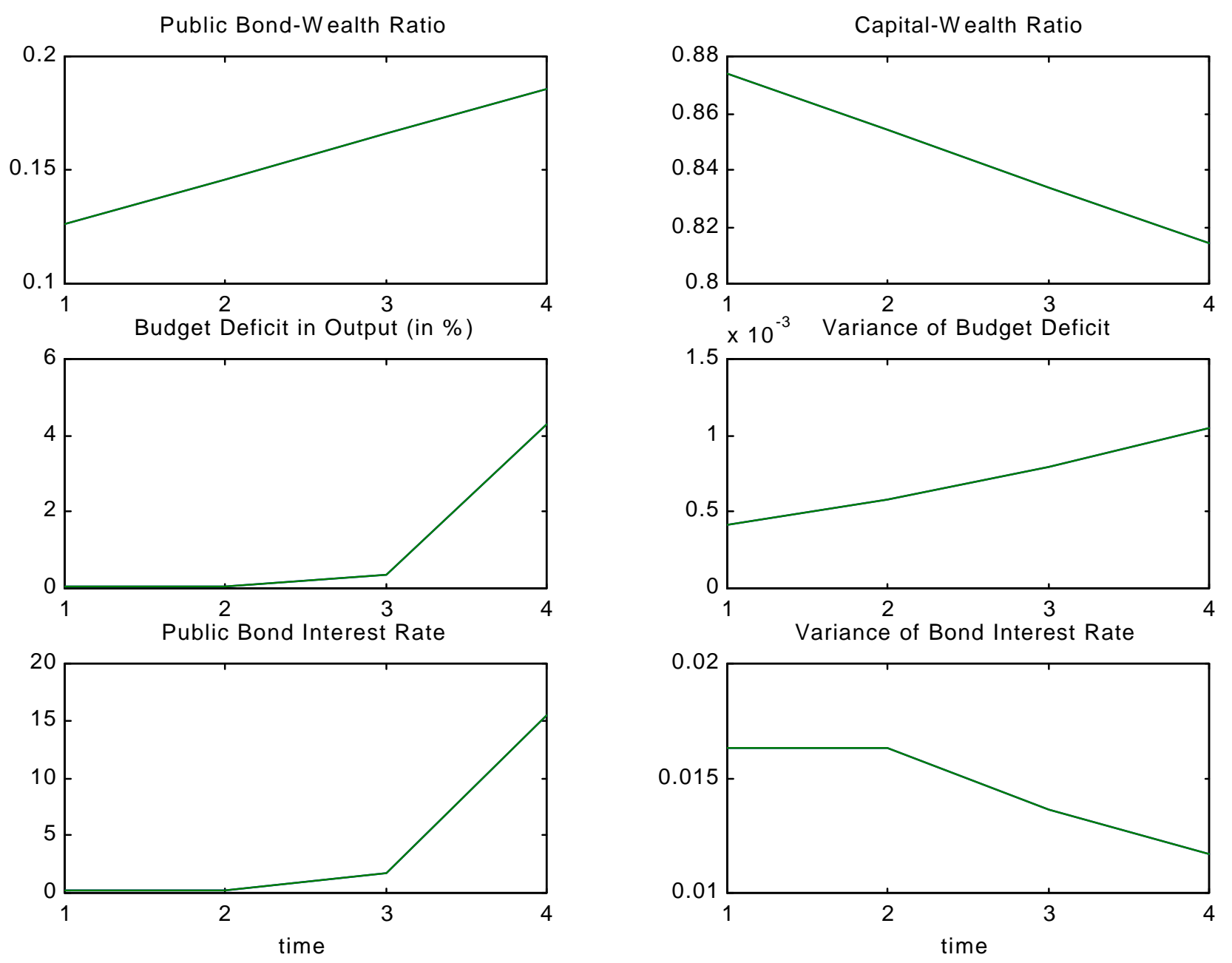
Figure 6.2: Adjustment to a Decrease in Parameter $\tau(\Delta \tau=-0.01)$
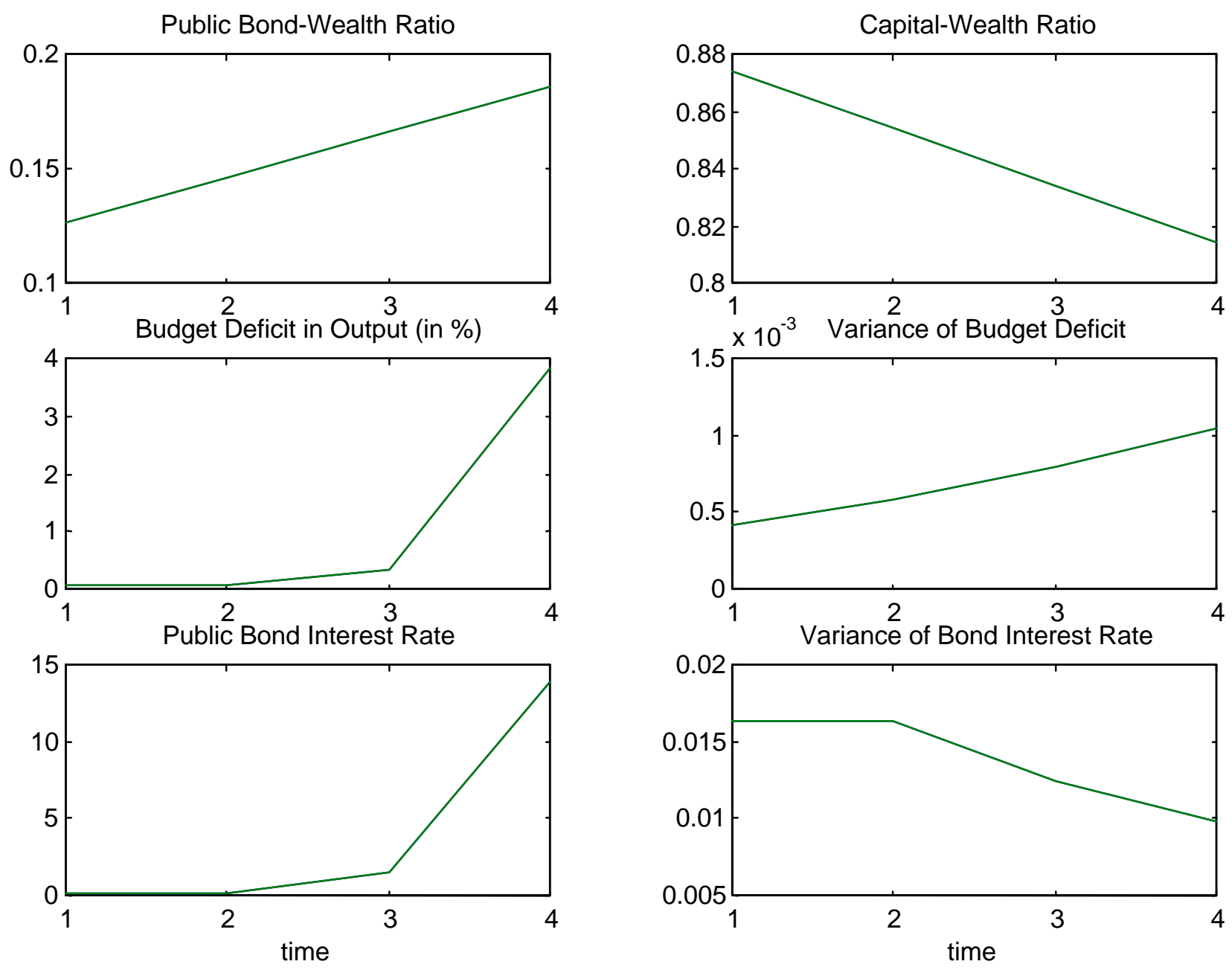


\subsection{The Effects of Technology and Expenditure Shocks}

In this subsection we turn to the analysis of changes in the parameters that describe technology and expenditure shocks, that is $\sigma_{z}^{2}, \sigma_{y}^{2}$ and $\sigma_{y z}$. As far as expenditure shocks are concerned, we examine the effect of a one percent increase in its variance $\left(\Delta \sigma_{z}^{2}=0.01\right)$. The adjustment to the shock is plotted in Figure 6.3. In this case the shock is fueled into the model through an initial change in $\sigma_{p}^{2}$. This means that the shock takes longer to affect the endogenous variables in the model. In fact, only in the second period will $n_{B}$ decrease, lowering the market demand for public bonds. As a result, the equilibrium $r_{B}$ decreases. In the third period, the new $r_{B}, \sigma_{p}^{2}$ and $\sigma_{p y}$ lead to a further decrease in the optimal $n_{B}$ and the process continues. The adjustment is again clearly unsustainable and the variables end up assuming values that are not realistic. In this situation the economy faces increasing average budget surpluses.

Next, we study the adjustment to a decrease in the variance of technology shocks $\left(\Delta \sigma_{y}^{2}=-0.005\right)$. The adjustment process is similar to those that we have been describing. The only difference is that the initial shock affects more deeply the equilibrium relations. Looking at equations 54, 55 and 35, it is evident that $\sigma_{y}^{2}$ is a parameter of vital importance. Nevertheless, this does not necessarily mean that its global effect is strong. In fact, the partial effects have opposing signs. Figure 6.4 plots the adjustment to the decrease in the variance of technology shocks. In this case, there is an increase in the optimal proportion of public bonds in the portfolio, an increase in average budget deficits as well as an increase in average public bond interest rate.

Finally, we examine the adjustment to a small increase in the covariance between technological and public expenditure shocks $\left(\Delta \sigma_{y z}=0.001\right)$. Here again, the shock takes longer to affect the endogenous parameters because it must first go through $\sigma_{p}^{2}$ and $\sigma_{p y}$. Figure 6.5 plots the adjustment to this last shock, which is qualitatively identical to the previous one.

At this point we state the main conclusions drawn from this section. First, it is clear that shocks on the exogenous parameters of the model put the budget deficit onto an unsustainable path. 
Figure 6.3: Adjustment to an Increase in Parameter $\sigma_{z}^{2}\left(\Delta \sigma_{z}^{2}=0.01\right)$
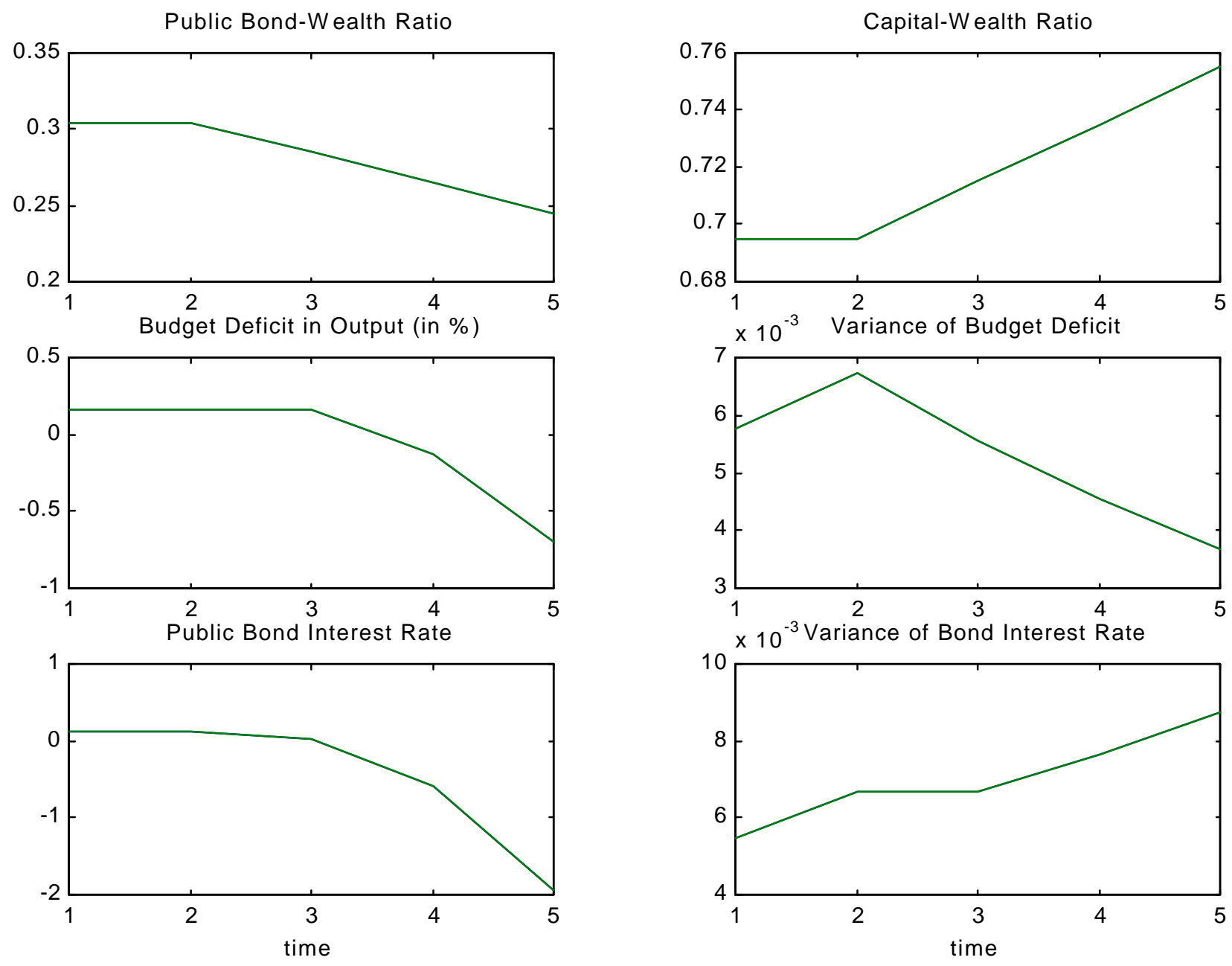
Figure 6.4: Adjustment to a Decrease in Parameter $\sigma_{y}^{2}\left(\Delta \sigma_{y}^{2}=-0.005\right)$
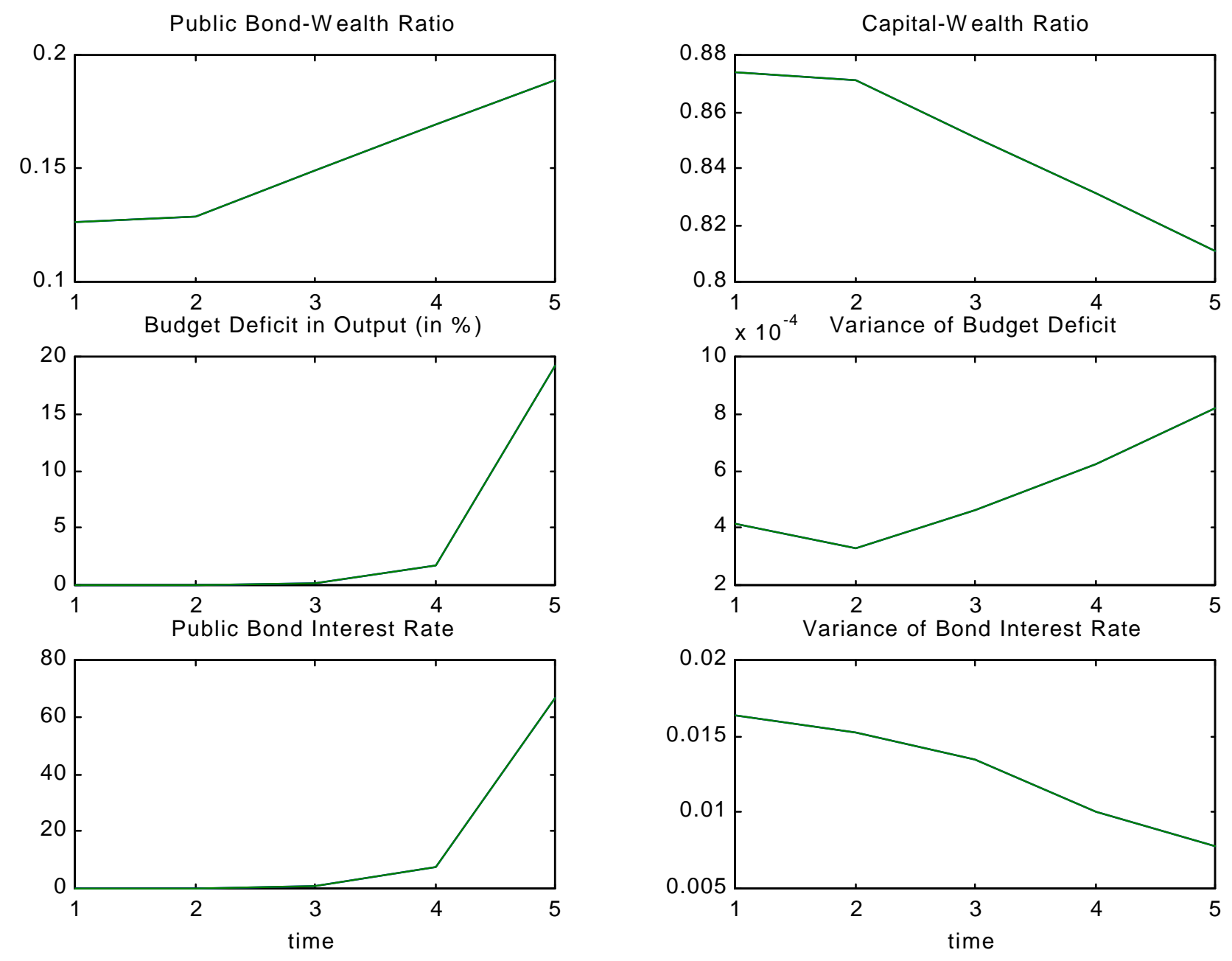
Figure 6.5: Adjustment to an Increase in Parameter $\sigma_{y z}\left(\Delta \sigma_{y z}=0.001\right)$
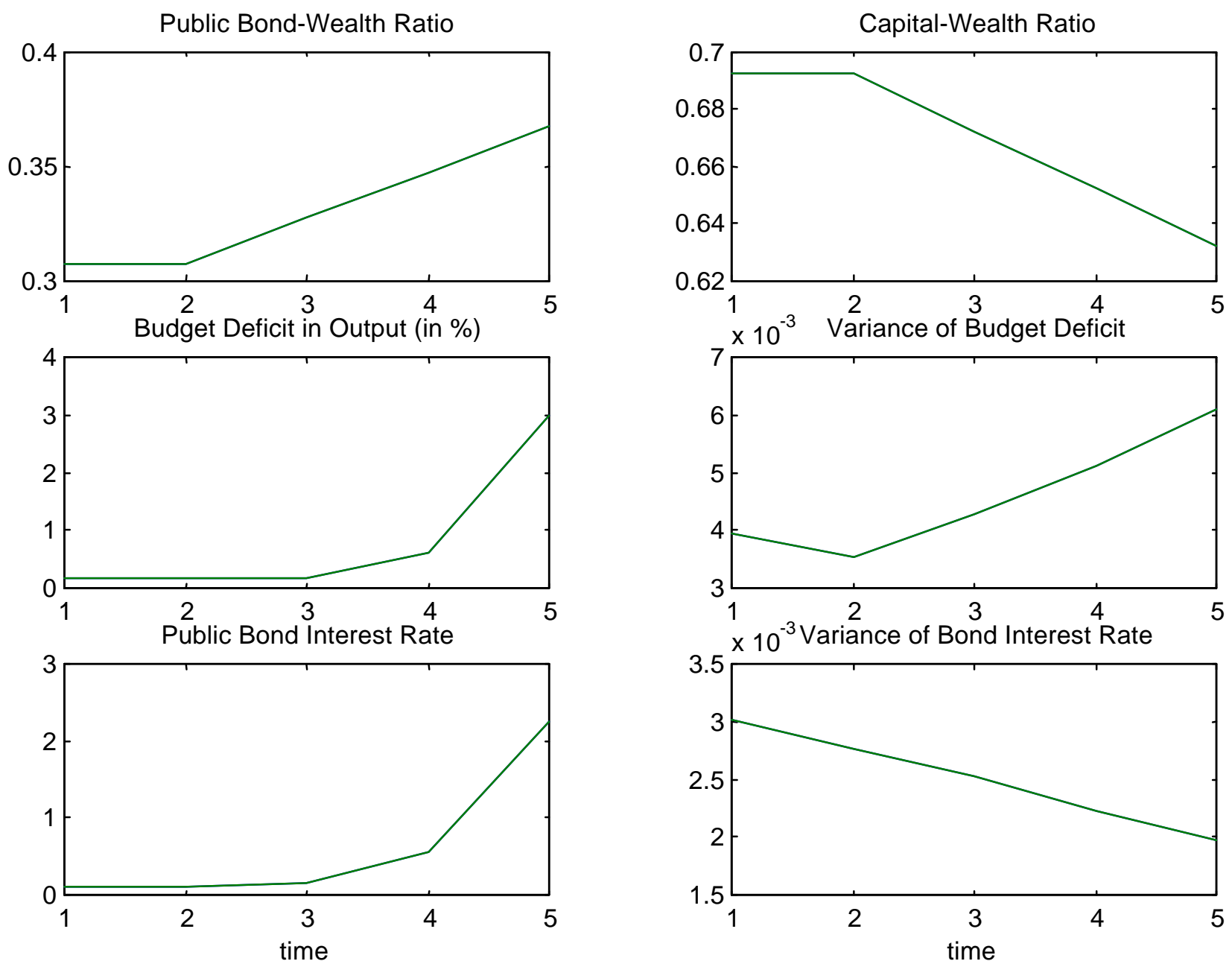
Such a result is not equivalent to saying that any type of shock leads to unsustainable budget deficit behaviour. We have only been examining the effect of shocks on the structural parameters of the economy. Note that the shortrun shocks in technology $(d y)$ and public expenditure $(d z)$, which occur in each period, are embodied in the stationary equilibrium that has been presented. Therefore, they do not imply unsustainable budget deficit behaviour.

In light of these results, policy authorities should be careful when changing structural parameters. As would be expected, higher average public expenditure or lower taxation leads to growing deficits. On the contrary, higher volatility in public expenditure shocks leads to average budget surpluses, as consumers turn to capital investment. It was also seen that a decrease in the variance of technology shocks leads to growing deficits. Therefore, an economy that moved into an environment with smaller technology shocks would tend to have a bad budget deficit performance. The same would happen to an economy that decided to run a less-active counter-cyclical expenditure policy. In fact, a higher covariance between technology and expenditure shocks increases the budget deficits. This is no problem in monetary unions as the absence of an independent monetary policy tends to be replaced by higher fiscal activism.

\section{Simulated Equilibrium Path of Variables and Comparative Dynamics}

In the previous section we studied the adjustment of the economy to shocks in the exogenous variables of the model. This analysis focused on changes in the growth rate of the endogenous variables, stressing the problem of the sustainability of the budget deficit. After having defined the stationary equilibrium budget deficit, this is clearly the important issue to discuss. As noted in Perotti, Strauch and von Hagen (1998), policy-makers in monetary unions are more worried about the risk of having a government whose financial position is moving out of control, than about any particular level of deficits and debts. These authors also stress that episodes where governments start to lose control of their public finances are not rare events. In the sample of 20 OECD countries after 1973 , they find 65 such events.

In this section we simulate the stationary equilibrium path of the endogenous variables for economies with different characteristics. This allows a comparative dynamics analysis. The simulations are built for 150 periods, following a monthly basis. The initial capital stock is set equal to 100 and the Cholesky factorisation is used to assure that technology and expenditure shocks match the calibrated values for variances and covariances. The aim of the simulations is to examine the equilibrium behaviour of the budget deficit in economies with two major types of differences. First, we compare two economies having identical stochastic structures but different tax and spending policies. Then, the opposite is done. We compare economies having identical spending and taxation parameters but different stochastic structures. 


\begin{tabular}{|c|c|c|c|c|c|c|c|c|}
\hline Parameter & $\alpha$ & $\beta$ & $g$ & $\tau$ & $\sigma_{y}^{2}$ & $\sigma_{z}^{2}$ & $\sigma_{y z}$ & $\psi$ \\
\hline Value & 0.15 & 0.05 & 0.25 & 0.3 & 0.03 & 0.03 & 0.0 & 0.055 \\
\hline Parameter & $n_{B}$ & $n_{K}$ & $\mu$ & $r_{B}$ & $\sigma_{p}^{2}$ & $\sigma_{p y}$ & $\sigma^{2}$ & $\sigma_{w}^{2}$ \\
\hline Value & 0.117 & 0.883 & 0.049 & 0.113 & 0.057 & 0.015 & 0.001 & 0.0007 \\
\hline
\end{tabular}

Table 2: Economy 1

\begin{tabular}{|c|c|c|c|c|c|c|c|c|}
\hline Parameter & $\alpha$ & $\beta$ & $g$ & $\tau$ & $\sigma_{y}^{2}$ & $\sigma_{z}^{2}$ & $\sigma_{y z}$ & $\psi$ \\
\hline Value & 0.15 & 0.05 & 0.2 & 0.35 & 0.03 & 0.03 & 0.0 & 0.048 \\
\hline Parameter & $n_{B}$ & $n_{K}$ & $\mu$ & $r_{B}$ & $\sigma_{p}^{2}$ & $\sigma_{p y}$ & $\sigma^{2}$ & $\sigma_{w}^{2}$ \\
\hline Value & 0.302 & 0.698 & 0.139 & 0.100 & 0.096 & 0.008 & 0.011 & 0.0007 \\
\hline
\end{tabular}

Table 3: Economy 2

In Tables 7.1 and 7.2 we present respectively Economy 1 and Economy 2 . These two economies have the same stochastic structure but Economy 1 runs a less rigorous fiscal policy than does Economy 2. In fact, its public spending represents a higher proportion of output and the tax rate is lower. The stationary equilibrium path of the variables is plotted in Figures 7.1 and 7.2.

The observation of these figures allows us to draw some conclusions. Firstly, it is obvious that the less rigorous economy (Economy 1) presents a better macroeconomic performance than does the rigorous one (Economy 2). In fact, Economy 1 presents a lower budget deficit-output ratio, a higher total wealth, a higher capital stock and a lower debt-output ratio. At this point, it is clear that Economy 1 can only run a comparatively less rigorous fiscal policy in the stationary equilibrium because it has a lower public debt. In other words, Economy 1 can only afford to run a less rigorous fiscal policy in the stationary equilibrium because it does not face the burden of high debt interest payments. Furthermore, the counterpart of not having a high public debt is to have a high capital stock, which implies higher output and higher tax receipts. In fact, Figure 7.2 shows that, despite having a lower tax rate, Economy 1 collects more taxes than does Economy 2. Lastly, it is important to remark that, despite the other differences, the average bond interest rate is similar in both countries. However, Economy 1 faces a larger bond interest rate variance. This means that less rigorous economies tend to face higher interest rate volatility.

Finally, Tables 7.3 and 7.4 introduce respectively Economy 3 and Economy 4. This second simulation compares the stationary equilibrium path of variables in economies having identical fiscal policy parameters but different stochastic structures. In fact, Economy 4 faces higher variances for technology and public expenditure shocks than does Economy 3. In addition, Economy 4 presents a negative covariance between the two types of shocks, while in Economy 3 they are independent. The stationary equilibrium path of variables is plotted in Figures 7.3 and 7.4.

These results allow us to derive a second set of conclusions. First, it is clear that the economy with more volatility (Economy 4) runs a smaller stationary 


\begin{tabular}{|c|c|c|c|c|c|c|c|c|}
\hline Parameter & $\alpha$ & $\beta$ & $g$ & $\tau$ & $\sigma_{y}^{2}$ & $\sigma_{z}^{2}$ & $\sigma_{y z}$ & $\psi$ \\
\hline Value & 0.15 & 0.05 & 0.25 & 0.3 & 0.01 & 0.01 & 0.0 & 0.055 \\
\hline Parameter & $n_{B}$ & $n_{K}$ & $\mu$ & $r_{B}$ & $\sigma_{p}^{2}$ & $\sigma_{p y}$ & $\sigma^{2}$ & $\sigma_{w}^{2}$ \\
\hline Value & 0.126 & 0.874 & 0.053 & 0.107 & 0.016 & 0.005 & 0.0004 & 0.0002 \\
\hline
\end{tabular}

Table 4: Economy 3

\begin{tabular}{|c|c|c|c|c|c|c|c|c|}
\hline Parameter & $\alpha$ & $\beta$ & $g$ & $\tau$ & $\sigma_{y}^{2}$ & $\sigma_{z}^{2}$ & $\sigma_{y z}$ & $\psi$ \\
\hline Value & 0.15 & 0.05 & 0.25 & 0.3 & 0.09 & 0.09 & -0.01 & 0.058 \\
\hline Parameter & $n_{B}$ & $n_{K}$ & $\mu$ & $r_{B}$ & $\sigma_{p}^{2}$ & $\sigma_{p y}$ & $\sigma^{2}$ & $\sigma_{w}^{2}$ \\
\hline Value & 0.084 & 0.916 & 0.035 & 0.140 & 0.348 & 0.076 & 0.0016 & 0.002 \\
\hline
\end{tabular}

Table 5: Economy 4

equilibrium budget deficit, a smaller debt-output ratio and a higher average public bond interest rate. Therefore, a high volatility in the shocks that affect the economy must be accompanied by a good budget deficit performance. Otherwise, the sustainability of public finances cannot be achieved. In addition, and as would be expected, the comparatively higher volatility of shocks on Economy 4 generates a higher variance for the endogenous variables in this economy. In fact, despite facing similar equilibrium average output growth rates, Economy 4 faces stronger booms and recessions than does Economy 3. In the next section we end the paper with some concluding remarks. 
Figure 7.1: Economy 1 (-) Economy 2 (--)
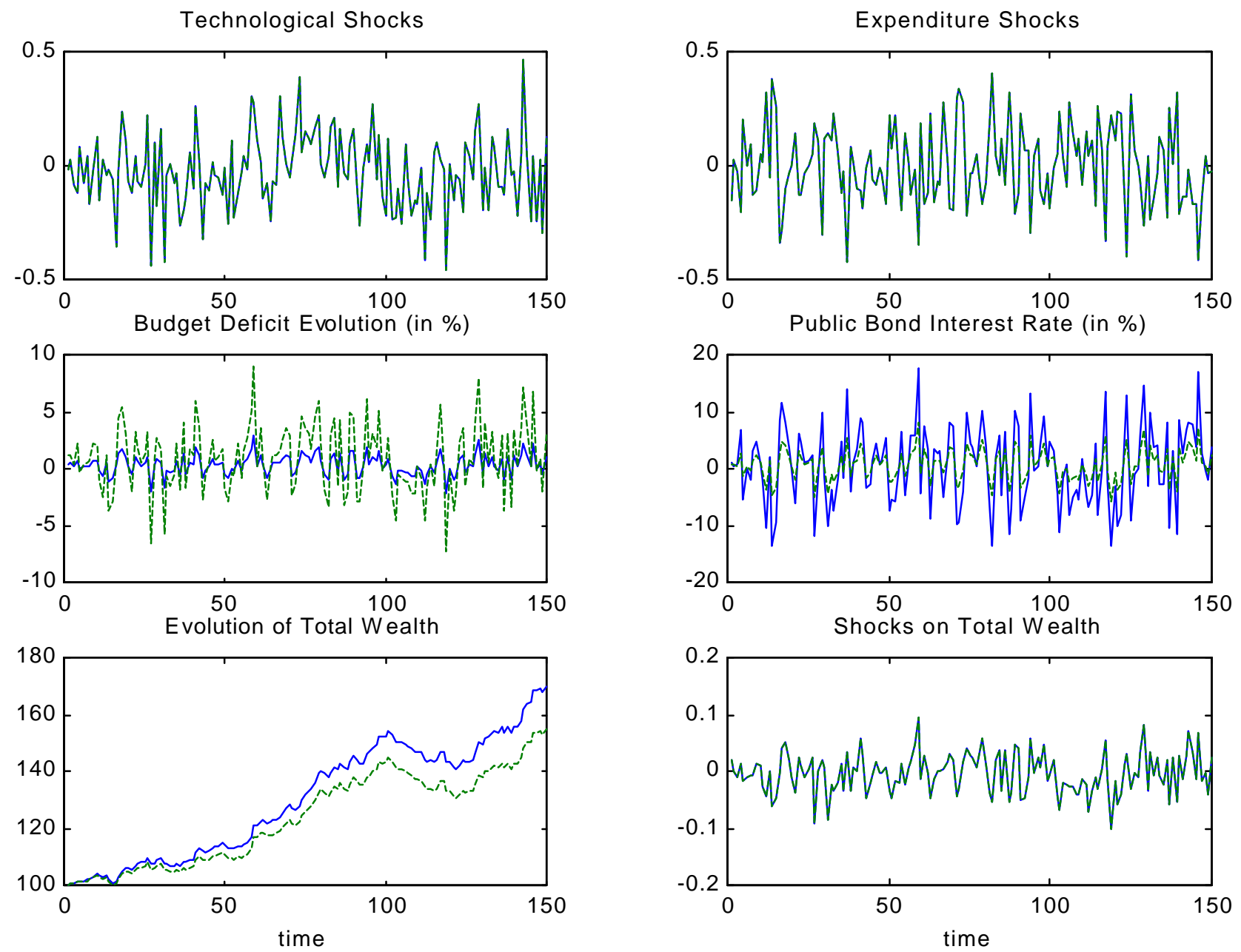
Figure 7.2: Economy 1 (-) Economy 2 (--)

Tax Receipts
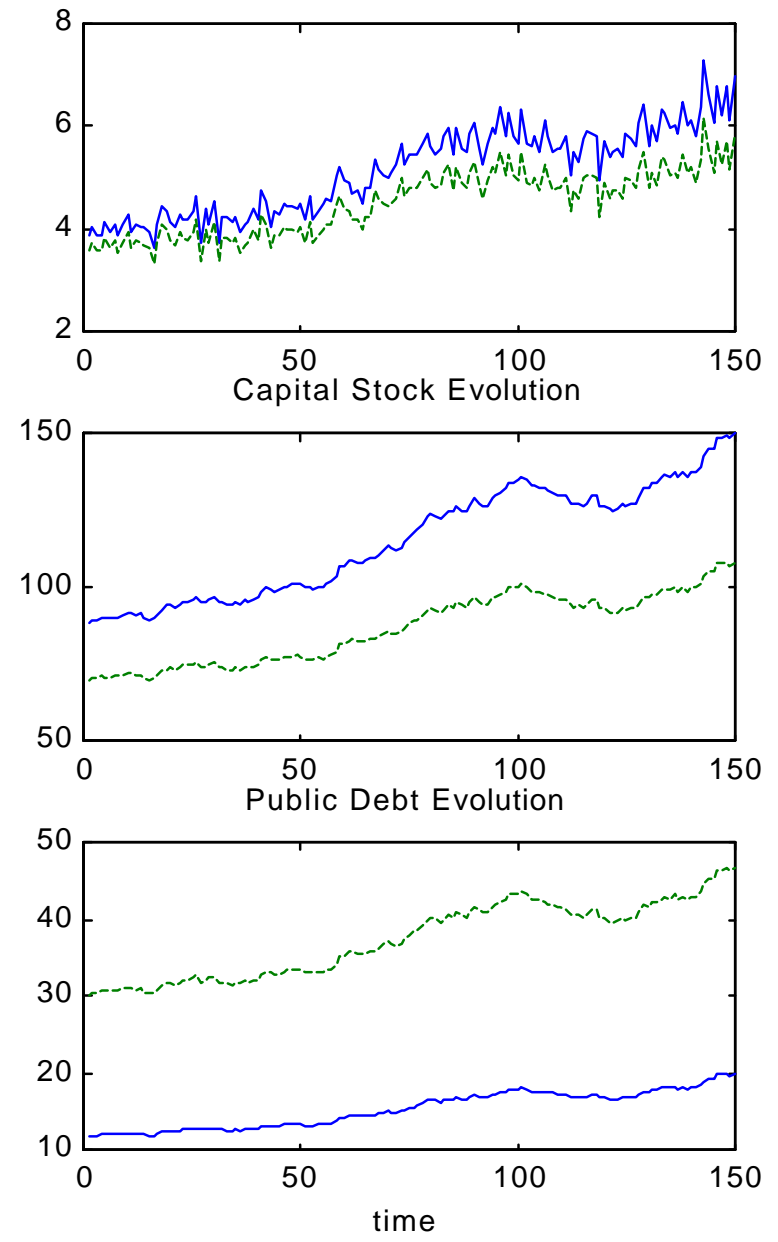

Total Public Expenditure
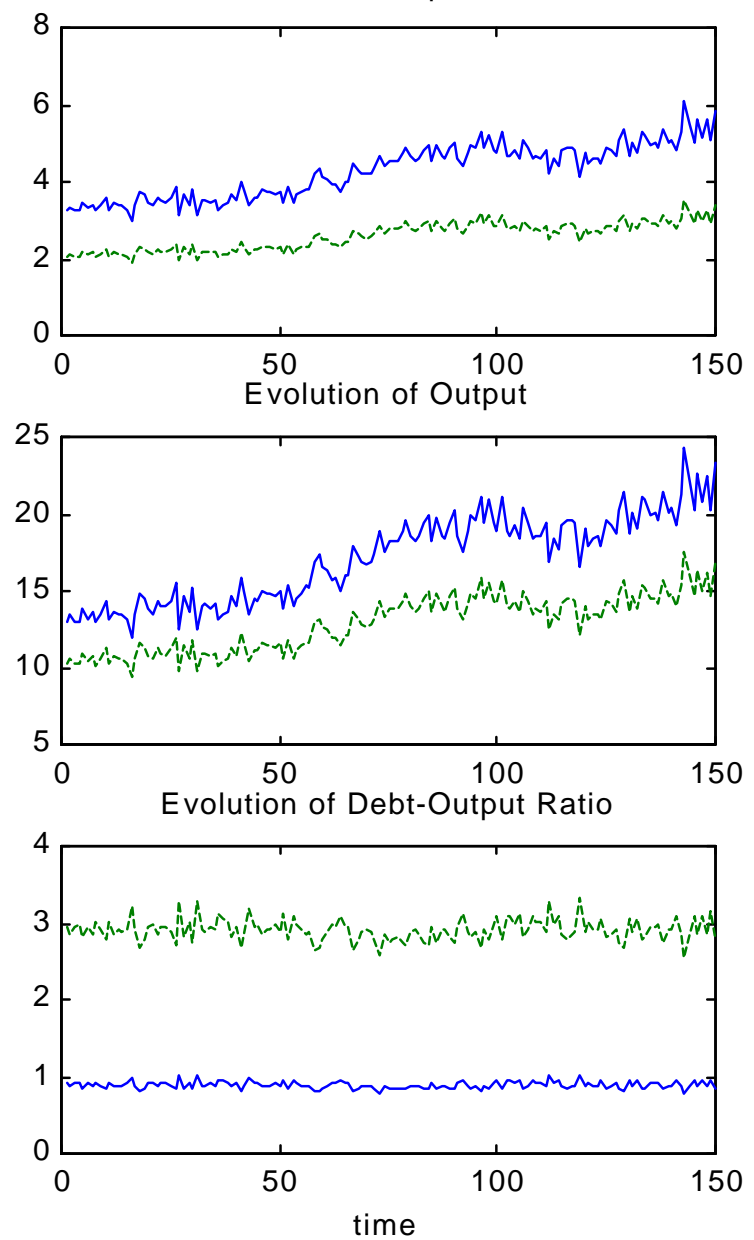
Figure 7.3: Economy 3 (-) Economy 4 (--)
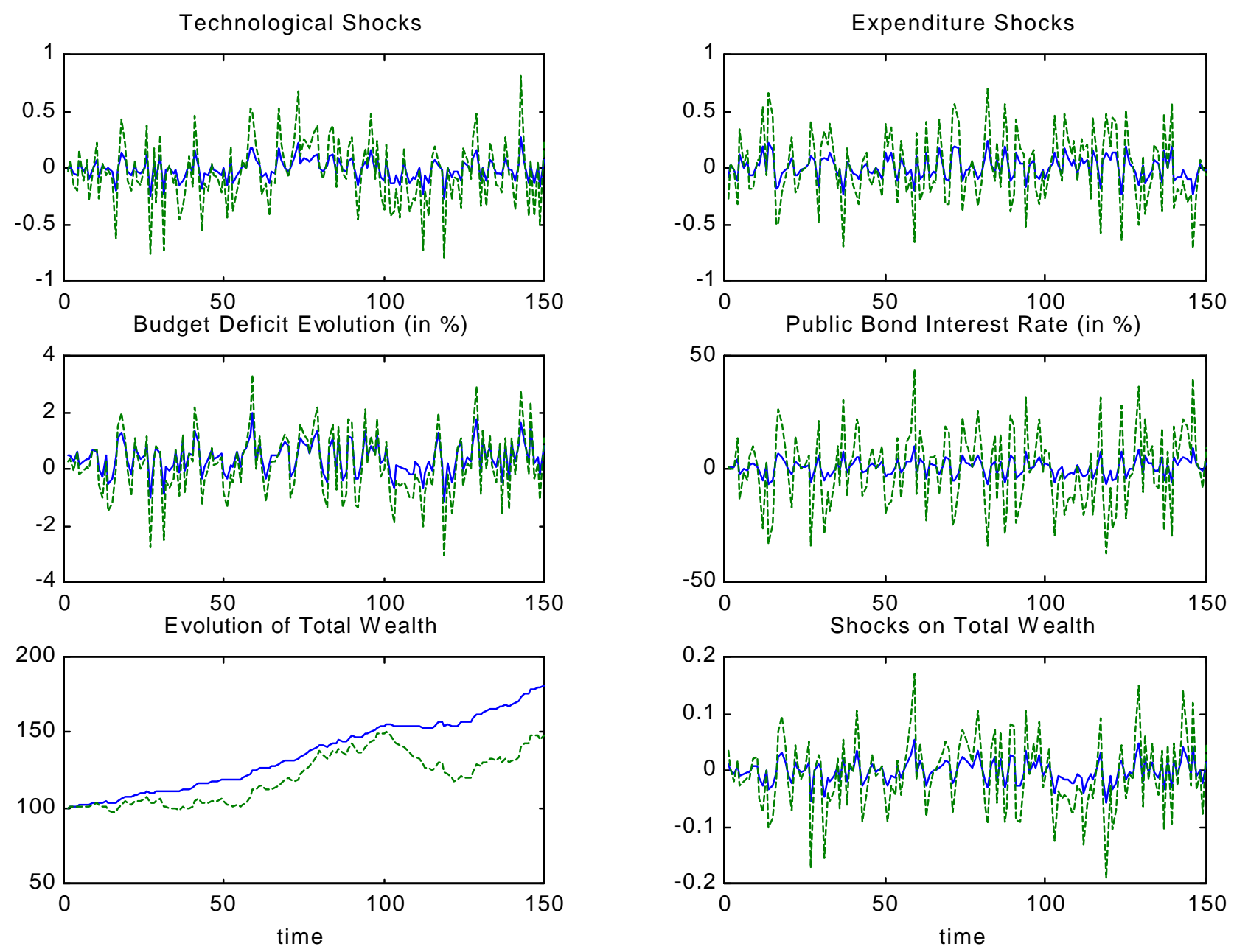
Figure 7.4: Economy 3 (-) Economy 4 (--)

Tax Receipts
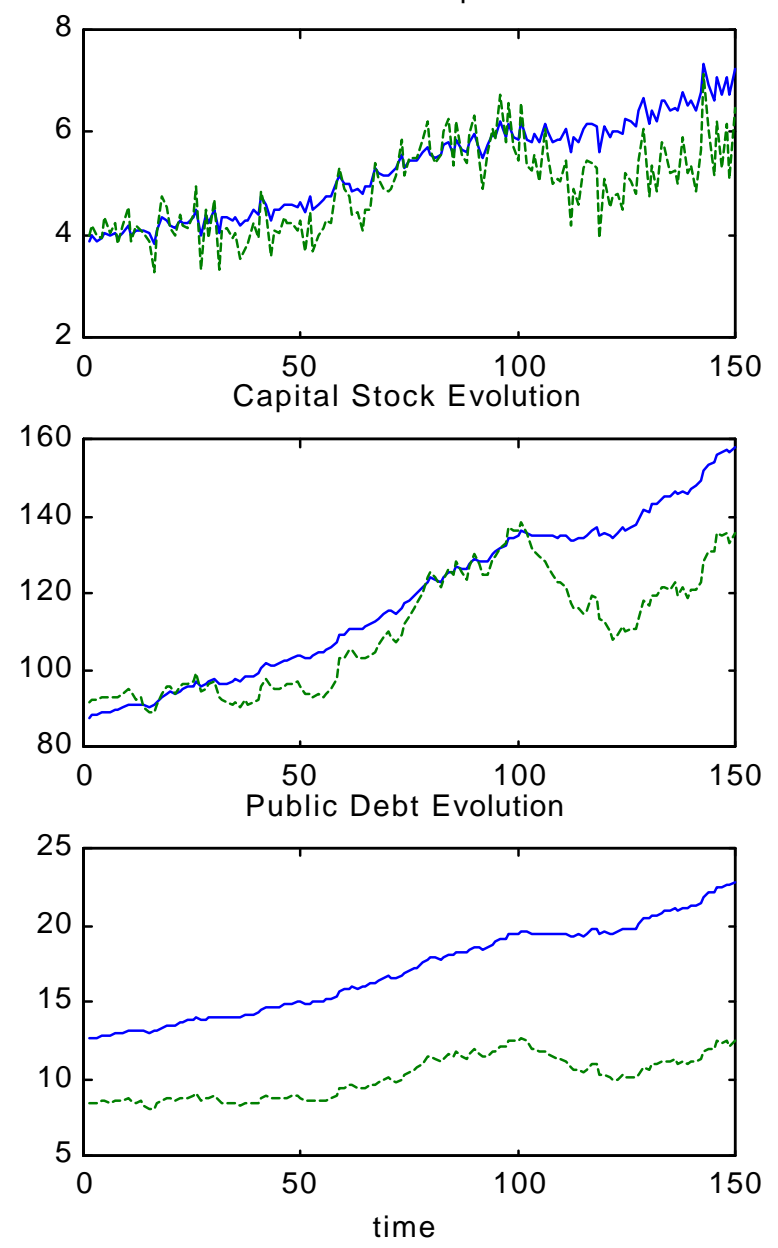

Total Public Expenditure
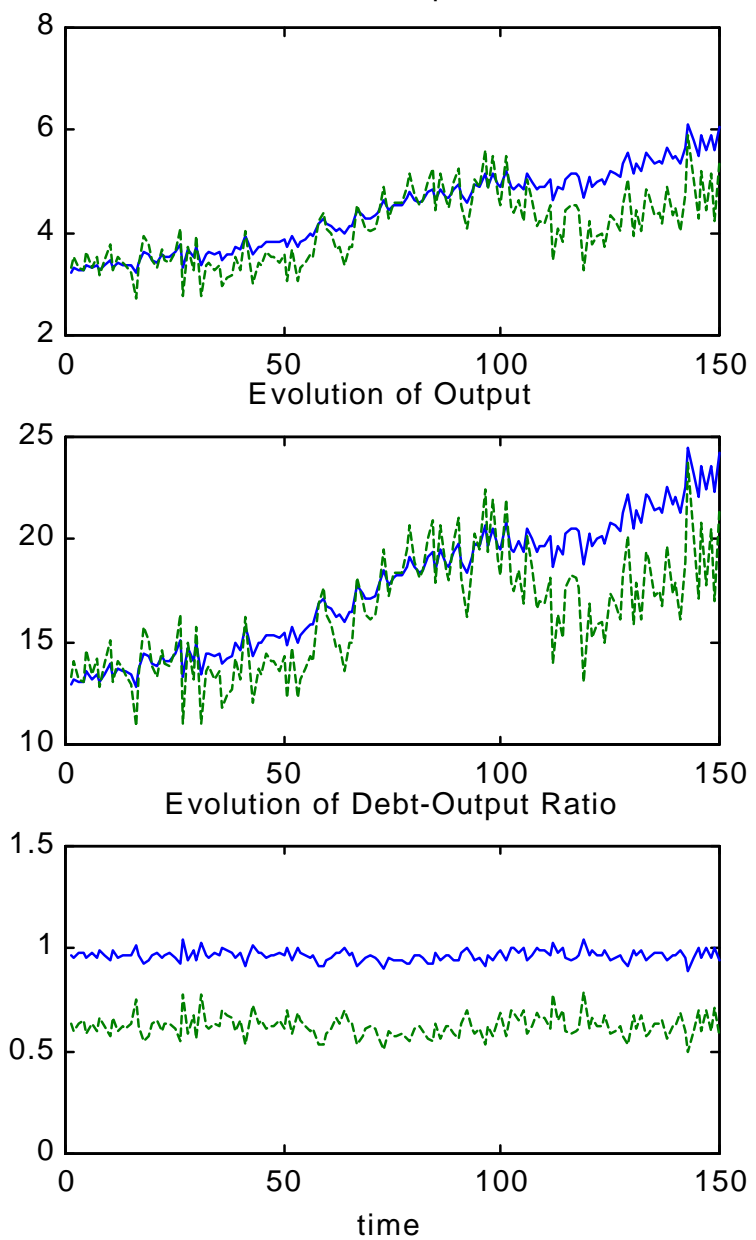


\section{Concluding Remarks}

In this last section we sum up the main results of the paper and discuss its limitations. The main point in the paper is the determination of the budget deficitdeterministic output ratio and the public bond interest rate in a stochastic, dynamic and general equilibrium framework. These two endogenous variables are derived as Brownian motions, whose average and variance are functions of the structural parameters of the economy. The remaining endogenous variables, namely the optimal proportions of assets in the portfolio, total output, total wealth, tax receipts and public expenditure, are obtained in a similar fashion.

We have examined how shocks on the structural parameters of the model affect the general equilibrium solution. It was observed that these shocks lead to unsustainable budget deficit and public bond interest rate adjustment paths. This occurs because, for reasonable values of the parameters, an increase in the public bond interest rate leads to an increase in the demand for bonds that is smaller than the corresponding increase in interest payments. In this sense, we have concluded that increased public expenditure or lower taxation leads to ever increasing budget deficits. On the contrary, an increase in the volatility of public expenditure shocks or an increase in the volatility of technology shocks leads to diminishing budget deficits.

Finally, we have compared the stationary equilibrium path of the endogenous variables in economies having different structures. It was seen that only economies with a low public debt-wealth ratio can afford to maintain large deficits in the stationary equilibrium. Furthermore, it was noted that a high volatility in technology and public expenditure shocks must be accompanied by a good budget deficit performance. Otherwise, the sustainability of public finances cannot be achieved.

Further research could explore the following avenues. Firstly, the explicit consideration of the international linkages would be very important. As we have mentioned above, this is a difficult task as it demands the modelling of the external demand and supply of public bonds. The general equilibrium solution becomes much more complex and it may not be defined in a closed form. Secondly, it would be interesting to define the simultaneous changes in the structural parameters while leaving the equilibrium budget deficit unaltered. This is also analytically complex in our general equilibrium framework but it might contain some interesting insights. 


\section{A Appendix}

This appendix derives the expression for the stochastic Lagrangian function in our model. The stochastic optimisation problem of the representative consumer was presented as:

$$
\underset{n_{B}, n_{K}, \frac{C}{W}}{\operatorname{Max}} E_{0} \int_{0}^{\infty} \frac{1}{\gamma}(C(t))^{\gamma} e^{-\beta t} d t
$$

Subject to:

$$
\begin{aligned}
& \frac{d W}{W}=\left(n_{B} r_{B}+n_{K} r_{K}(1-\tau)-\frac{C}{W}\right) d t+d w \\
& n_{B}+n_{K}=1
\end{aligned}
$$

The value function of the problem $V(W, t)$ depends on the state variable $W$ and on time $t$. Then, the differential generator of the value function results from the limit:

$$
\begin{aligned}
\lim _{d t \rightarrow 0} E_{t}\left(\frac{d V(W, t)}{d t}\right) \equiv & L_{W}[V(W, t)] \\
\equiv & \frac{\partial V}{\partial t}+\left(n_{B} r_{B}+n_{K} r_{K}(1-\tau)-\frac{C}{W}\right) W \frac{\partial V}{\partial W} \\
& +\frac{1}{2} \sigma_{w}^{2} W^{2} \frac{\partial^{2} V}{\partial W^{2}}
\end{aligned}
$$

Note that $E\left[W^{2} d w d w\right]=\sigma_{w}^{2} W^{2}$, where $\sigma_{w}^{2}$ is the variance of the stochastic variable $d w$. In order to simplify the expression above, we set $\rho=n_{B} r_{B}+$ $n_{K} r_{K}(1-\tau)$, which defines the net rate of return of the portfolio. Thus:

$$
L_{W}[V(W, t)]=\frac{\partial V}{\partial t}+\left(\rho-\frac{C}{W}\right) W \frac{\partial V}{\partial W}+\frac{1}{2} \sigma_{w}^{2} W^{2} \frac{\partial^{2} V}{\partial W^{2}}
$$

It is also necessary to build the stochastic Bellman equation of the problem. Using the Bellman principle, the value function can be written as:

$$
\begin{aligned}
V(W(t), t)= & \underset{\frac{C}{W}, n_{K}, n_{B}}{\operatorname{Max}} E_{t} \int_{t}^{t+d t} \frac{1}{\gamma}[C(s)]^{\gamma} e^{-\beta s} d s+ \\
& +\underset{\frac{C}{W}, n_{K}, n_{B}}{\operatorname{Max}} E_{t+d t} \int_{t+d t}^{\infty} \frac{1}{\gamma}[C(s)]^{\gamma} e^{-\beta s} d s
\end{aligned}
$$


then, taking the limit when $d t \rightarrow 0$ it becomes:

$$
V(W)=\underset{\frac{C}{W}, n_{K}, n_{B}}{\operatorname{Max}}\left\{\frac{1}{\gamma}[C(s)]^{\gamma} e^{-\beta s} d t+E_{t}[V(W(t+d t), t+d t)]\right\}
$$

Therefore, value function can be written as:

$$
V(W)=\underset{\frac{C}{W}, n_{K}, n_{B}}{M a x}\left\{\frac{1}{\gamma}(C(s))^{\gamma} e^{-\beta s} d t+V(W)+E_{t} d V\right\}
$$

Subtracting $V(W(t), t)$ from both sides of the equality and dividing by $d t$, it becomes:

$$
0=\underset{\frac{C}{W}, n_{K}, n_{B}}{\operatorname{Max}}\left\{\frac{1}{\gamma}(C(s))^{\gamma} e^{-\beta s}+E_{t} \frac{d V}{d t}\right\}
$$

Making use of the definition of differential generator, the expression above is written simply as:

$$
0=\underset{\frac{C}{W}, n_{K}, n_{B}}{\operatorname{Max}}\left\{\frac{1}{\gamma}(C(s))^{\gamma} e^{-\beta s}+L_{W}[V(W, t)]\right\}
$$

Finally, given the time separable utility function, the value function depends only on $t$ for the effect of time discounting. Therefore, $V(W, t)=e^{-\beta t} X(W)$ and the stochastic Lagrangian function becomes:

$$
£=\frac{1}{\gamma}(C(t))^{\gamma} e^{-\beta t}+L_{W}\left[e^{-\beta t} X(W)\right]+e^{-\beta t} \lambda\left[1-n_{B}-n_{K}\right]
$$

or equivalently:

$$
\begin{aligned}
£ & =\frac{1}{\gamma}\left(\frac{C}{W}\right)^{\gamma} W^{\gamma} e^{-\beta t}-\beta e^{-\beta t} X(W)+\left(\rho-\frac{C}{W}\right) W \frac{\partial X}{\partial W} e^{-\beta t} \\
& +\frac{1}{2} \sigma_{w}^{2} W^{2} \frac{\partial^{2} X}{\partial W^{2}} e^{-\beta t}+e^{-\beta t} \lambda\left[1-n_{B}-n_{K}\right]
\end{aligned}
$$




\section{B Appendix}

This appendix derives the equation for the stability of the debt-income ratio as it is presented in the classical public finance theory. The debt-income ratio is defined as:

$$
b=\frac{B}{P Y}
$$

where $B$, is the nominal stock of debt, $P$ is the price level and $Y$ is the level of real output. In addition, the increase in the debt from one period to the other equals the budget deficit. Therefore:

$$
\Delta B=i B_{t}-x P_{t} Y_{t}
$$

where $i$ is the nominal interest rate and $x$ is the primary surplus relative to income. Next, the change of the debt-income ratio can be calculated as:

$$
\Delta b=\frac{B_{t}+\Delta B_{t}}{P_{t} Y_{t}(1+y)(1+\pi)}-b_{t}
$$

where $y$ is the growth rate of output and $\pi$ is the inflation rate in the economy. The previous equation can be simplified to obtain:

$$
\Delta b=b\left[\frac{1+\Delta B / B}{(1+y)(1+\pi)}-1\right]=q b\left[1+\frac{\Delta B}{B}-(1+y)(1+\pi)\right]
$$

with $q=1 /(1+y)(1+\pi)$. Finally, substituting equation 85 in 87 we obtain:

$$
\Delta b=q b[1+i-(1+y)(1+\pi)]-q x
$$

which, using the approximation $(1+y)(1+\pi) \simeq 1+y+\pi$ simplifies to:

$$
\Delta b=q[(i-\pi-y) b-x]
$$

This is the equation for the stability of the debt-income ratio that we wanted to obtain. 


\section{References}

[1] Alesina, A. and Perotti, R., 1995, "The Political Economy of Budget Deficits", IMF Staff Papers, vol 42, no 1, 1-31.

[2] Alesina, A. and Perotti, R., 1996, "Fiscal Discipline and the Budget Process", American Economic Review, vol 86, nº 2, 401-407.

[3] Barro, R., 1989, "The Ricardian Approach to Budget Deficits", Journal of Economic Perspectives, Spring 89, vol 3, nº 2, 37-54.

[4] Bernheim, B., 1989, "A Neoclassical Perspective on Budget Deficits", Journal of Economic Perspectives, Spring 89, vol 3, nº 2, 55-72.

[5] Blanchard, O. and Fischer, S., 1989, Lectures on Macroeconomics, MIT Press.

[6] Blanchard, O., 1985, "Debt, Deficits and Finite Horizons", Journal of Political Economy, vol 93, no 21, 223-247.

[7] Bohn, H., 1995, "The Sustainability of Budget Deficits in a Stochastic Economy", Journal of Money, Credit and Banking, 27(1), 257-271.

[8] Buiter, W., 1985, "A Guide to Public Sector Debt and Deficits", Economic Policy, ${ }^{\circ} 1$, November 1985, 14-79.

[9] Chow, G.,1978, "Optimum Control of Stochastic Differential Equation Systems", Journal of Economic Dynamics and Control, 1, 143-145.

[10] Corsetti, G., 1997, "A Portfolio Approach to Endogenous Growth: Equilibrium and Optimal Policy", Journal of Economic Dynamics and Control, $21,1627-1644$.

[11] Cunha, L. and Machado, J., 1991, "Aritmética da Dívida Pública: Portugal e a UEM", Revista Economia, 15(2), 171-207.

[12] Easterly, W. and Hebbel, K., 1994, "Fiscal Adjustment and Macroeconomic Performance: A Synthesis", in Public Sector Deficits and Macroeconomic Performance, ed. by W. Easterly, A. Rodrogiez and K. Hebbel, World Bank.

[13] Eichengreen, B., 1997, "European Monetary Unification: Theory, Practice and Analysis", MIT Press.

[14] Emerson, M. et al., 1992, "One Market, One Money", Oxford University Press.

[15] Gaspar, V., 1992, "Budgetary Rules and Procedures in EMU", WP FEUNL $\mathrm{n}^{\circ} 193$.

[16] Gagales, A., 1991, "Evaluating the Sustainability of Fiscal Deficits", Greek Economic Review, vol 13, $\mathrm{n}^{\circ} 2,215-250$. 
[17] Hamilton, J., 1994, Time Series Analysis, Princeton University Press.

[18] Kenen, P., 1995, Economic and Monetary Union in Europe, Cambridge University Press.

[19] Kloden, P. and Platen, E., 1992, Numerical Solution of Stochastic Differential Equations, Springer.

[20] Malliaris, A. and Brock, 1982, W., Stochastic Methods in Economics and Finance, North-Holland.

[21] Mongelli, F., 1999, "The Effects of the European Economic and Monetary Union (EMU) on Fiscal Sustainability", Open Economies Review, vol 10, 31-61.

[22] Musgrave, R. and Musgrave, P., 1989, Public Finance in Theory and Practice, 5th edition, McGraw-Hill.

[23] Nielsen, S., 1992, "A Note on the Sustainability of Primary Budget Deficits", Journal of Macroeconomics, vol 14, $\mathrm{n}^{\circ} 4,745-754$.

[24] Poterba, J., 1996, "Budget Institutions and Fiscal Policy in the U.S. States", American Economic Review, vol 86, nº 2, 395-400.

[25] Perotti, R., Strauch, R. and von Hagen, J., 1998, Sustainability of Public Finances, CEPR and ZEI.

[26] Sargent, T. and Wallace, N., 1981, "Some Unpleasant Monetarist Arithmetic", Federal Reserve Board of Minneapolis, Quarterly Review, Fall 81, $1-17$.

[27] Sargent, T., 1987, Dynamic Macroeconomic Theory, Harvard University Press. 
[28] Torres, F. and Giavazzi, F.(eds.), 1993, Adjustment and Growth in the European Monetary Union, Cambridge University Press.

[29] Turnovsky, S., 1995, Methods of Macroeconomic Dynamics, MIT Press, Cambridge, Massachusetts.

[30] Turnovsky, S., 1997, International Macroeconomic Dynamics, MIT Press, Cambridge, Massachusetts. 